UNIVERSIDADE DE SÃO PAULO

FACULDADE DE ADMINISTRAÇÃO, ECONOMIA E CONTABILIDADE

DEPARTAMENTO DE ECONOMIA

PROGRAMA DE PÓS-GRADUAÇÃO EM ECONOMIA

\title{
The TED Spread as a Risk Factor in The Cross \\ Section of Stock Returns
}

Victor Westrupp

Orientador: Prof. Dr. Rodrigo De Losso da Silveira Bueno

Co-orientador: Prof. Dr. Bruno Cara Giovannetti

JULHO 2012

São Paulo 
Prof. Dr. João Grandino Rodas

Reitor da Universidade de São Paulo

Prof. Dr. Reinaldo Guerreiro

Diretor da Faculdade de Economia, Administração e Contabilidade

Prof. ${ }^{a}$ Dra. Elizabeth Maria Mercier Querido Farina

Chefe do Departamento de Economia

Prof. Dr. Pedro Garcia Duarte

Coordenador do Programa de Pós-Graduação em Economia 
Victor Westrupp

\section{The TED Spread as a Risk Factor in The Cross Section of Stock}

\section{Returns}

Dissertação apresentada ao Departamento de Economia da Faculdade de Economia, Administração e Contabilidade da Universidade de São Paulo como requisito para a obtenção do título de Mestre em Ciências.

Orientador: Prof. Dr. Rodrigo De Losso da Silveira Bueno Co-Orientador: Prof. Dr. Bruno Cara Giovannetti

JULHO 2012

Versão Original

São Paulo 
FICHA CATALOGRÁFICA

Elaborada pela Seção de Processamento Técnico SBD/FEA-USP

\section{Westrupp, Victor}

The TED spread as a risk factor in the cross section of stock returns / Victor Westrupp - São Paulo, 2012.

$64 \mathrm{p}$.

Dissertação (Mestrado) - Universidade de São Paulo, 2011

Orientador: Rodrigo De Losso da Silveira Bueno.

Co-orientador: Bruno Cara Giovannetti.

1. Finanças 2. Econometria 3. Crédito

I. Universidade de São Paulo. Faculdade de Economia, Administração

e Contabilidade. II. Título. 
À minha família 


\section{AGRADECIMENTOS}

Agradeço, em primeiro lugar, aos meus pais, Vera e Celso, pelo apoio incondicional que recebi durante minha vida e minha trajetória acadêmica. Esta dissertação sem dúvidas, é muito mais deles do que minha propriamente. Reconheço também o apoio da minha irmã Jacqueline.

Em segundo lugar, agradeço aos excelentes professores e profissionais da área econômica com que tive contato. Ao Prof. Dr. Alex Luiz Ferreira pelo apoio e incentivo em busca do mestrado acadêmico, e à todos os professores e colegas de Economia da FEA-RP, onde passei ótimos cinco anos da minha vida. Agradeço também aos professores do IPE-USP pelo ensino de excelência que obtive no mestrado acadêmico.

Cabe um agradecimento especial ao meu orientador, Prof. Dr. Rodrigo De Losso da Silveira Bueno, e ao meu co-orientador, Prof. Dr. Bruno Cara Giovannetti, pelas excelentes críticas recebidas ao longo do desenvolvimento do trabalho, e por todo o apoio que recebi em busca da continuação dos estudos. Tamanho apoio dificilmente eu teria recebido em qualquer outra circunstância e lhes sou imensamente grato. Saibam que fiz o meu máximo para merecer o reconhecimento e a confiança depositados em mim. Agradeço também aos professores Mauro Rodrigues Jr., Pedro Garcia Duarte e Marcos de Almeida Rangel pelos incentivos recebidos para a continuação dos estudos.

Em terceiro lugar, agradeço aos colegas e monitores do mestrado do IPE-USP, que se tornaram a minha segunda família. Às excelentes discussões que tínhamos na "sala do café", e ao apoio nos tempos difíceis dos estudos incessantes. Devo todo o meu trajeto aos senhores.

Agradecimentos especiais à Dejanir Henrique da Silva e Heitor Sandes Pellegrina, auxílio indispensável que recebi no preparo do application, à Murilo Moraes e Anna Olímpia pelo sábados, domingos e feriados que compartilhamos no IPE, e à André Zílio, Paulo Manoel, Eduardo De Nardi Ros, Alexandre Pécora, Luis Meloni, João Basto e André Mazini, pessoas que considero verdadeiros amigos.

Por último, agradeço à $\mathrm{CNPq}$, pelo apoio financeiro. 
"Banco é onde nos emprestam guarda-chuvas quando faz sol e pedem de volta quando ameaça chover". Robert Frost 


\section{RESUMO}

Esta dissertação apresenta evidência empírica da TED Spread como um fator the riscp na cross-section dos retornos de ações. Portfólios com elevada sensibilidade à TED Spread possuem elevados retornos médios ajustados para outros fatores de risco. O apreçamento do risco de TED Spread é especialmente forte entre small caps. TED Spread é uma medida usual de dificuldades de financiamento em mercados interbancários e o resultado obtido é consistente com o modelo Margin-CAPM de Gârleanu and Pedersen (2011) 


\begin{abstract}
We provide empirical evidence of the TED spread as a risk factor in the cross-section of stock returns. Portfolios with high sensitivities to the TED spread have high average risk-adjusted returns. The pricing of TED spread risk is especially strong among small caps. TED spread is a usual measure of funding difficulties in interbank markets and our results are consistent with the Margin-CAPM model of Gârleanu and Pedersen (2011).
\end{abstract}




\section{Summary}

List of Tables $\quad$ XV

List of Figures $\quad$ xvii

1. Introduction . . . . . . . . . . . . . . . . . . . . 1

2. Related Literature . . . . . . . . . . . . . . . . . . 4

3. TED Spread and Margin-based Asset Pricing Model . . . . . . . . . . . 7

$3 . .1 \quad$ TED Spread . . . . . . . . . . . . . . 7

$3 . .2 \quad$ Margin-Based Asset Pricing Model . . . . . . . . . . . . . . . 8

4. Empirical Analysis . . . . . . . . . . . . . . . . . . . . 11

$4 . .1 \quad$ Cross Section Analysis . . . . . . . . . . . . . . . . 11

4.1.1 Data....................... 11

4..1.2 Cross Section of Stock Returns . . . . . . . . . . . . 11

4..1.3 Size and TED spread risk . . . . . . . . . . . . 18

$4 . .2$ Cross Section Analysis - Constant TED Betas . . . . . . . . . 20

$4 . .3$ TED Betas and Margin Requirements . . . . . . . . . . 23

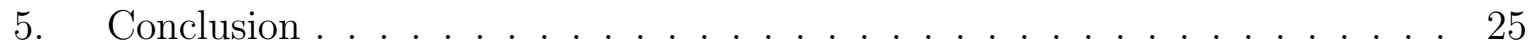

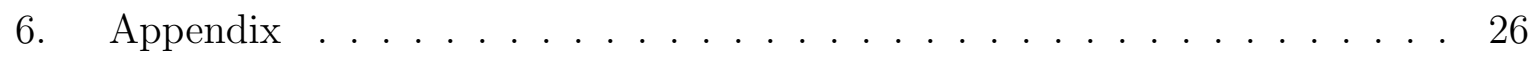

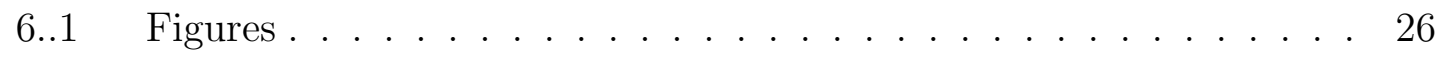

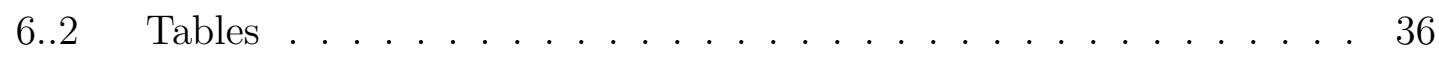

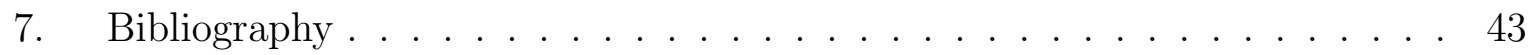




\section{List of Tables}

1 Alphas on 10 post ranking portfolios - Time-varying Betas. . . . . . . . . 36

2 GMM estimates of TED premium and expected TED spread using timevarying sorted portfolios . . . . . . . . . . . . . . . . . . 37

3 Alphas on 10 post ranking portfolios divided by size groups. . . . . . . . . 38

4 Alphas on 10 post ranking portfolios - Constant Betas . . . . . . . . . . . 39

5 GMM estimates of TED premium and expected TED spread - 10 Expost Portfolios built using Constant Betas . . . . . . . . . . . . . . . . . . . . . 40

$6 \quad$ Alphas on 10 post ranking portfolios divided by size groups - Constant Betas 41

$7 \quad \operatorname{BEKK}(1,1)$ model for TED spread and S\&P 500 excess returns . . . . . . 42 


\section{List of Figures}

1 TED Spread in annualized rates $(\%) \ldots \ldots \ldots \ldots$

2 Relative Margins (\%), Monthly volatility (Volm,\%) and VaR (VaR_RiskM_m,

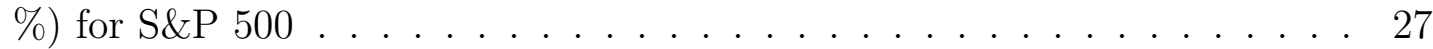

3 Post-ranking TED betas and annualized average returns (\%) from portfolios sorted on time-varying TED betas - 3-Factor model . . . . . . . . . . . . 28

4 Post-ranking TED betas and annualized average returns (\%) for 30 sizeTED portfolios built using time-varying betas - 3 Factor model . . . . . . . 29

5 Post-ranking TED betas and annualized average returns (\%) for 10 sizeTED portfolios built using time-varying betas: small size . . . . . . . . . .

6 Post-ranking TED betas and annualized average returns (\%) for 10 sizeTED portfolios built using time-varying betas: medium size . . . . . . . . 30

$7 \quad$ Post-ranking TED betas and annualized average returns (\%) for 10 sizeTED portfolios built using time-varying betas: big size . . . . . . . . . . . 30

8 Post-ranking TED betas and annualized average returns (\%) from portfolios sorted on constant TED betas - 3-Factor model . . . . . . . . . . . . . . . 31

9 Post-ranking TED betas and annualized average returns (\%) for 30 sizeTED portfolios built using Constant Betas - 3-Factor model . . . . . . . . 32

10 Post-ranking TED betas and annualized average returns (\%) for 10 sizeTED portfolios built using Constant Betas: small size . . . . . . . . . . . . 32

11 Post-ranking TED betas and annualized average returns (\%) for 10 sizeTED portfolios built using Constant Betas: medium size . . . . . . . . . . 33

12 Post-ranking TED betas and annualized average returns (\%) for 10 sizeTED portfolios built using Constant Betas: big size . . . . . . . . . . . . 33

13 Estimated Variance and Covariance from prior $\operatorname{BEKK}(1,1)$ model . . . . . 34

14 Relative margin requirements for futures contracts on the S\&P 500 index

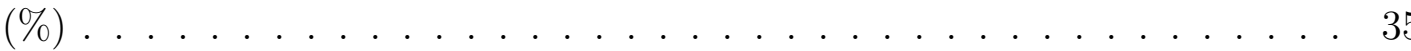


xviii 


\section{Introduction}

We provide empirical evidence of the TED Spread as a risk factor in the cross section of stock returns. The TED spread is the difference between the short-term 3-month LIBOR Euro-dollar rate and the short-term 3-month Treasury Bill rate and can be interpreted as the difference between an uncollateralized interbank debt rate and a collateralized standard debt rate. It can be considered a risk factor because it captures the additional cost (in terms of total wealth) financial agents have to cover funding expenses, i.e. to fund leverage positions in the market. In times when the spread is high, the additional cost to cover funding expenses rises, and stocks more exposed to funding difficulties become less attractive to financial investors. An additional premium is thus required to compensate this additional difficulty.

Evidence of the TED Spread as a risk factor may contribute to understand asset prices in times of financial distress, since positive spreads are related to times of credit restrictions. When credit liquidity falls, collateral markets are not able to provide as much liquidity as they want to, turning financial institutions towards interbank markets in order to cover possible margin calls, or fund new portfolio purchases. Interbank rates spike up, generating a positive spread ${ }^{1}$.

Recent experiences regarding financial crisis also serve as motivation to understand the adverse effects of funding difficulties on asset prices. In the 2007-2010 financial crisis, as stated by Brunnermeier (2008), leveraged agents faced difficulties for funding their positions while liquidity dried up and frictions limited optimal risk sharing among them (i.e., expert agents were not able to fund their desired portfolios, since credit was restricted). In the 1987 "program trading" crisis, an enormous volume of margin calls made interbank debt rates spike up, and those who did not meet margin calls liquidated their positions, pressuring financial markets down (for a better discussion, see Carlson (2006)) $)^{2}$.

\footnotetext{
${ }^{1}$ Also, one could think that collateralized debt rates would fall, since financial agents would not lend as much as they wanted to, given elevated margin requirements. Interest rates would be suboptimal in such situation, falling to attract new investments, and contributing to increase the spread.

${ }^{2}$ Other recent financial distress times are in the LTCM collapse in 1998, the Asian currency crisis of
} 
Given previous motivation, the main objective of this present work is to analize whether TED spread constitutes a risk factor to stock market decisions, i.e. whether TED spread is priced in terms of an additional premium required to attract stocks more exposed to funding difficulties. Results in the cross section of stock returns go in favor of the presence of the "TED Spread risk", and once we divide stocks by size groups, results in favor of the TED Spread risk are even stronger among small size stocks, an expected result given that small stocks may be more exposed to funding difficulties.

In order to provide a theoretical reason why agents may consider TED spread as a risk factor, we use the Margin-based Asset Pricing Model of Gârleanu and Pedersen (2011), one that relates margin requirements ${ }^{3}$ with asset prices $^{4}$. During "good times", credit is unconstrained and leverage operations face no additional costs that would make them more expensive or even prohibitive (margin requirements are easily covered). In such scenario, margins would not help explain expected asset returns. However, during "bad times", highly leveraged investment banks or hedge-funds may be unable to fund their losing positions and collapse, dragging other financial agents into funding problems. Not only margin requirements but also TED spread (which is equal to the shadow cost of funding) increase fiercefully. Margin requirements may constrain leveraged agents' decisions, increasing the cost of such financial operations. Expected returns should increase in order to compensate for the additional cost, especially for high-margin assets, which now use more of the expensive capital.

According to the model, highly exposed assets to the shadow cost of funding should pay a higher premium, and margin requirements capture just how exposed the asset is

1997, the dot-com boom of 1998-2000 and the "09/11" event of 2001.

${ }^{3}$ Margin requirement is the amount of money that must be paid using the borrower's own capital in order to finance leverage positions in the market. Consider the example of a hedge fund that requests a loan to buy a specific stock portfolio. Suppose that portfolio costs $\$ 1000$. Using the portfolio as collateral, the lender will request a fraction of the portfolio to be financed with the borrower's own capital, say $20 \%$ of the portfolio's value, given risks involved (market price fluctuations, for example). In this case, the hedge fund will borrow only $\$ 800$, using $\$ 200$ from its own capital to purchase the portfolio, and we say that the portfolio has a margin requirement of $\$ 200$ (20\% in relative terms).

${ }^{4}$ As Brunnermeier (2008) mentioned, during the 2007 financial crisis, one of the mechanisms that amplified shocks on asset prices was related to rises in margin requirements (which forced agents into liquidating their positions, driving asset prices down and reducing their available collateral) 
to the funding cost. Given that margins vary through time, cross section analysis should consider time-varying TED betas, and its dynamics associated with state variables related to margin requirements. We follow Shanken (1990) and Pastor and Stambaugh (2003) and use conditional time-varying TED betas to build "TED exposed" portfolios, ranking assets according to its TED Spread exposure.

Results are favorable to the presence of the TED premium. The " 1 minus 10 " strategy (going long in the most exposed portfolio to the TED spread, and short in the least exposed) pays excess returns of $2.622 \%$ annually (controlling for other risk factors), but what is somewhat surprising is that the TED spread has a significant relevance in pricing small size stocks, generating an excess return of $5.89 \%$ (significant at 90\%). We also estimated the "TED spread premium", obtaining significant results.

Cross section tests were implemented to ordinary stocks traded in NYSE, AMEX and NASDAQ since 1982 until 2010. The period used reflects data availability of margins on $\mathrm{S} \& \mathrm{P}$ futures. It is a relevant period of time, considering the number of credit constraining events.

In order to provide robustness to our predictions, we applied the cross section test to the "constant beta" case, where TED spread betas are not driven by state variables. We also analyzed whether relative margins do covary with the asset's exposure on the TED spread. We show that time-varying TED betas obtained on Multivariate GARCH process of S\&P 500 excess returns and TED spread walk almost together with S\&P 500 relative margin requirement.

The rest of the paper is organized as follows: section 2 presents related literature to margin-based models and evidence of the TED Spread premium so far; section 3 presents the margin-based asset pricing model of Gârleanu and Pedersen (2011); section 4 gives a brief discussion of the TED spread and empirical results of the cross section of expected stock returns, as well as evidence supporting the relationship between the margins and asset's exposure on the TED spread; section 5 concludes the paper. 


\section{Related Literature}

Studies relating margin requirements and the shadow cost of funding to asset prices (hence, the presence of TED Spread risk) in a credit constrained environment are found in Luttmer (1996), Bernardo and Welch (2003) and more recently in Brunnermeier and Pedersen (2009), Ashcraft et al. (2010) and Gârleanu and Pedersen (2011). Those articles assume that agents are heterogeneous in a sense that they differ in their relative risk aversion and may face different margin constraints for taking leverage positions. During times of crisis, as capital is constrained, expected returns are positively related to margins because agents face additional costs of funding. Credit constraints can also cause adverse impacts on asset prices, and the worst of all, according to Gârleanu and Pedersen (2011) is the failure of the "Law of One Price" (LoOP), by which two different assets with similar cash flows are negotiated under different prices, as margin requirements may differ. Also, Hedegaard (2011) studied margin impacts on commodity future returns, and found that an increase in futures margins, in which speculators hold long positions, reduces the futures price of long-term contracts.

The literature of margins and asset prices is primarily related to the literature of borrowing constraints and agency costs as in Bernanke and Gertler (1989) and Kiyotaki and Moore (1997). In a credit constrained environment, assets like machinery or land not only serve as factors of production, but they also serve as collateral for bank loans. Borrowers' credit limit and asset prices are endogenously determined and this mechanism helps to explain the persistence of technology shocks and business cycles.

Results of credit difficulties and their impacts on asset prices are also relevant to understand unconventional monetary policies, as implied by Cecchetti et al. (2000), and recently by Geanakoplos (2010) and Ashcraft et al. (2010). Those papers argument that central bank's policy of decreasing interest rates during bad times may be inefficient in a margin constrained environment. Decreases in interest rates increase the shadow cost of funding, thus increasing the relative cost of investment in assets subject to high margin 
requirements, raising expected asset returns.

In Ashcraft et al. (2010), margin constraints may adversely affect macroeconomic aggregates. Given that margins increase expected returns, such mechanism lowers investment and output and increases the persistence of productivity shocks. Consequences of such shocks are not proportional to all economic sectors, since margin-elevated sectors will suffer more severely than others, as investors will reallocate capital towards low-haircut assets.

In Geanakoplos (2010), the discussion is mainly about the existence of a "leverage cycle" in which leverage operations are very frequent during good times and extremely restricted during bad times, causing adverse impacts on asset prices and other aggregate factors. This specific cycle is not a consequence of an unusual behaviour. Every agent is acting rationally in their individual point of view, and even if they remember past collapses, they will answer to the designed incentives and continue to propagate the cycle unless margins are regulated.

The discussion is relevant for the debate about whether central banks should increase lending facilities during bad times. According to Ashcraft et al. (2010), asset demands are quite sensitive to haircuts. The evidence is based on the new Term Asset-Backed Securities Loan Facility (TALF), a Federal Reserve credit facility to assist credit markets, lowering haircuts in order to reduce required returns. Although the program has been only implemented for newly issued securities, yields went down when the TALF program was announced and implemented.

Although great advances were made in the theoretical side of the problem, empirical evidence of the presence of TED Spread risk on asset returns seems to be lacking. Lashgari (2000) tries to explain current S\&P 500 returns using changes in TED spread as an independent variable in a linear regression, obtaining a negative significant coefficient. Bianchi and Drew (2010) use the TED spread as proxy for systemic risk, and analyze its impact on hedge fund returns. Giovannetti and Martins (2011) investigated the cross 
section incorporating the TED Spread as a risk factor, finding favorable results. They also investigated whether returns could be predicted by TED Spread movements, finding that future returns comove positively with changes in TED Spread.

Regarding the margin model's performance, Gârleanu and Pedersen (2011) analyzed the CDS-bond basis, which is the price discrepancy between securities with nearly identical economic exposure, but different margin requirements. The difference is due to the fact that corporate bonds not only require use of capital but are also illiquid, but its respective CDS is a derivative with zero present value and can be traded in secondary markets. Margins for CDS will respond only to economic counterparty risks, and thus, will be lower than corporate bonds margins.

Given empirical evidence so far, the present work helps to fill this gap in the literature of empirical asset pricing by analyzing the presence of TED Spread risk in the cross section of stock returns, supported by a theoretical model that relates TED Spread exposition to margin requirements. Next section analyzes the TED Spread more closely and presents the Margin-based asset pricing model of Gârleanu and Pedersen (2011). 


\section{TED Spread and Margin-based Asset Pricing Model}

We briefly discuss the TED spread in its theoretical terms and relate it to previous financial crisis. We also present the margin-based asset pricing model in general terms as a candidate to justify why asset markets price TED spread risk.

\section{3..1 TED Spread}

TED spread is the difference between the (short term) LIBOR 3-month Euro-dollar rate (an average of interest rates offered in the London interbank market for 3-month dollardenominated loans) and the (short term) 3-month Treasury Bill rate. It represents how difficult it is to obtain credit in collateralized debt markets: as soon as credit dries up, financial institutions turn to interbank loans, increasing interbank debt rates, thus increasing the spread. It could be seen as a measure of aggregate credit liquidity in financial markets.

Theoretically, one could think of the TED Spread as the difference between two riskless assets: one is negotiated in an interbank market and does not require collateral for loans, but is restricted only to financial agents, such as investment banks or hedge funds, and the other is a standard collateralized debt rate. The collateralized loan is less expensive than the interbank loan, but it requires collateral and may be restricted in times of financial distress, since usual agents who lend in such market (pension funds, for example) are extremely risk averse.

Now consider a financial agent whose portfolio is used as collateral and who uses interbank money to cover margin requirements. Suppose that the interbank rate is $r_{t}^{u}$, and the collateralized debt rate is $r_{t}^{c}$. The amount used to finance margin requirements could alternatively buy collateralized debt papers, earning $r_{t}^{c}$. Hence, the difference between $r_{t}^{u}$ and $r_{t}^{c}$ captures the additional cost (in terms of total wealth) the agent has to cover funding expenses. In specific terms, the spread between these two rates is equal to the 
shadow cost of funding. When the spread is high, the additional cost to cover funding expenses rises, reflecting the difficulty of funding leverage positions.

Looking historically to its time series, Figure 1 shows the end-of-the-month TED spread rates since April 1982 until December 2010. Most of the time, the spread remained close to $0.5 \%$ (or 50 basis points, which is a hundred times the percentage value), but when credit is restricted, the spread is usually above $1 \%$.

Figure 1 here.

Spikes of the TED are usually related to times of higher default risk. During the 2007 financial crisis, the observed spread was the highest in the whole series ( $5.3 \%$ annually). Not only interbank rates spiked up, but also T-Bill rates fell down, contributing to increase the spread. The "program trading" crisis of 1987 ("Black Monday" event of October 1987) also observed a TED spread peak, almost 3\% annually, due to an enormous volume of margin calls in the period. The 1998-2001 period does not show a very high spread, but it is quite volatile, showing that interbank rates probably reacted to difficulties in funding positions.

\section{3..2 Margin-Based Asset Pricing Model}

In this section, we present the basic structure of the Margin-based Asset Pricing Model of Gârleanu and Pedersen (2011) in order to understand how the TED spread is related to asset prices in equilibrium. The model is an endowment economy allocated between consumption, a set of risky assets and two riskless assets: (i) A collateralized debt asset and (ii) an uncollateralized interbank debt asset. Agents in the model are divided in two groups:

a) Risk averse agents: they are able to leverage in asset markets, but it is exogenously 
assumed that margins are not binding for their decisions. They are not allowed to take uncollateralized debt. These agents are usually lenders in collateralized debt markets, and are represented by pension funds in general. Their equilibrium condition is the standard CCAPM as in Breeden (1979):

$$
\mu_{t}^{i}-r_{t}^{c}=\gamma_{a} \beta_{t}^{C^{a}, i}, \quad \beta_{t}^{C^{a}, i}=\operatorname{cov}\left(\frac{d C^{a}}{C^{a}}, \frac{d P^{i}}{P^{i}}\right)
$$

Where $\mu_{t}^{i}$ is the expected asset return, $P_{t}^{i}$ is current asset price, $\gamma_{a}$ is its relative risk aversion $\left(\gamma_{a}>1\right)$, and $C_{t}^{a}$ is its consumption.

b) Risk tolerant agents (bravers): mostly take leverage positions but are subject to margin constraints. Margins must be financed with their own capital or with uncollateralized bonds. They capture the behavior of hedge-funds and investment banks in the economy. Their equilibrium condition is the standard CCAPM plus an additional factor that accounts for the additional premium demanded, since assets with higher margin requirements will be more expensive and less attractive in times of credit restrictions (positive TED spread).

$$
\mu_{t}^{i}-r_{t}^{c}=\beta_{t}^{C^{b}, i}+\psi_{t} m_{t}^{i}, \quad \beta_{t}^{C^{b}, i}=\operatorname{cov}\left(\frac{d C^{b}}{C^{b}}, \frac{d P^{i}}{P^{i}}\right)
$$

Where $m_{t}^{i}$ is the asset's relative margin requirement and $\psi_{t}=r_{t}^{u}-r_{t}^{c}$ is the shadow cost of funding (TED spread, in empirical terms). The additional premium is the shadow cost of funding times the relative margin requirement. It is easy to see that assets with higher margin requirements are more exposed to the shadow cost of funding, and required premium is higher as well.

Combining both conditions to obtain the economy's equilibrium condition, the additional premium demanded to compensate for the cost of funding is adjusted by the braver's relative consumption, a measure of relative importance of such group in aggregate consumption. The result is the "Margin CCAPM" of Gârleanu and Pedersen (2011)

$$
\mu_{t}^{i}-r_{t}^{c}=\gamma_{t} \beta_{t}^{C, i}+m_{t}^{i} \psi_{t} x_{t}, \quad \beta_{t}^{C, i}=\operatorname{cov}\left(\frac{d C}{C}, \frac{d P^{i}}{P^{i}}\right), \quad x_{t}=\frac{C_{t}^{b}}{\frac{C_{t}^{a}}{\gamma^{a}}+C_{t}^{b}}
$$


Where $C_{t}=C_{t}^{a}+C_{t}^{b}$, and $x_{t}$ is the measure of relative importance of risk tolerant agents in aggregate consumption. Such measure is also called the risk bearing capacity of risk tolerant agents because relative consumption is directly related to the amount of risk that group tolerates.

The model above is named "Margin CCAPM" in the sense that it is similar to standard CCAPM model, but in addition to the covariance risk-premium factor, there is the presence of a second term that accounts for additional risk given difficulties in funding.

The "Margin CAPM" can be derived assuming the market portfolio as the one that mostly covary with consumption.

$$
\mu_{t}^{i}-r_{t}^{c}=\lambda_{t} \beta_{t}^{i}+x_{t} \psi_{t} m_{t}^{i}, \quad \beta_{t}^{i}=\frac{\operatorname{cov}_{t}\left(\frac{d P^{q}}{P^{q}}, \frac{d P^{i}}{P^{i}}\right)}{\operatorname{var}_{t}\left(\frac{d P^{q}}{P^{q}}\right)}
$$

We base our empirical analysis on equation (3.4). It states that return premiums may be explained by a factor that accounts for funding difficulties (more especifically, the TED Spread), aside from the market factor. Next section presents data, methodology and results from the cross section of stock returns. 


\section{Empirical Analysis}

This section is destined to present empirical results of the presence of TED Spread risk among stock returns. Data and methodology, along with numerical results, are detailed in the next subsections.

\section{4..1 Cross Section Analysis}

\section{4..1.1 Data}

Empirical analysis of TED spread on asset prices uses ordinary stocks traded in NYSE, AMEX and NASDAQ. Their monthly returns are given by CRSP database codes 10 and 11. For interest rates, the Federal Reserve Database of St. Louis (FRED) has data on LIBOR Euro-dollar 3-month rates as well as the 3 month T-Bill. Factor portfolios used in cross-sectional analysis are from the Kenneth French website.

The sample starts at April 1982 and ends at December 2010. It starts in 1982 because the data on margins for S\&P 500 futures are available by the CME only after April 1982. While some might consider it a very short period of analysis, it is important to stress that this period was marked by a series of credit restriction events (The stock crash of 1987, Asian currency crisis of 1997, The financial crisis of 2007, among others already mentioned) and therefore, we condider it relevant to our analysis.

\section{4..1.2 Cross Section of Stock Returns}

In order to observe if a desired variable constitutes a risk factor, cross-sectional regressions are performed by incorporating other known risk factors such as market return, size and book-to-market, along with the tested factor. We want to test whether assets with higher exposure to the shadow cost of funding (TED spread) should pay more returns. Our asset 
pricing model is initially given by

$$
r_{t}^{e, i}=\alpha^{i}+\left(\beta^{F, i}\right)^{\top} F_{t}+\beta^{T E D, i} \mathrm{TED}_{t}+e_{t}^{i}
$$

where $\alpha^{i}$ is the time series intercept ${ }^{5}, F_{t}$ is a $k \mathrm{x} 1$ vector of common risk factors and $e_{t}^{i}$ is an idiosyncratic shock. $\left(\beta^{F, i}\right)$ is the $k \mathrm{x} 1$ vector of factor loadings, and $\beta^{T E D, i}$ is the TED beta, it captures how exposed the asset is to the TED Spread.

Once we are guided by the Margin-based Asset Pricing model, some modifications could be proposed to equation (4.5) in order to improve empirical analysis. Following equation (3.4), the "margin factor" is composed of three variables, the shadow cost of funding $\left(\psi_{t}\right)$, the risk bearing of risk tolerant agents $\left(x_{t}\right)$ and individual margin requirements $\left(m_{t}^{i}\right)$. As mentioned before, the ideal proxy for $\psi_{t}$ is the TED spread, since it represents the spread between an uncolatteralized interbank rate and a collateralized debt rate.

For the bravers risk bearing capacity $x_{t}$, notice that it represents the ratio of consumption flows (adjusted by respective risk aversions). Since consumptions from both groups are not expected to deviate in terms of consumption growth, assuming a constant risk bearing capacity seems reasonable for empirical analysis.

For individual margins, the spot market do not track relative margins on buy-on-margin operations, which makes them unobservable variables for our analysis. Nonetheless, we could divide the margin-based asset pricing equilibrium into two complementary stories: (i) assets that co-move more with the shadow cost of funding should pay more returns. These assets are more exposed to funding difficulties, increasing the required premium; and (ii) an asset's exposure to the shadow cost of funding is directly related to margin requirements.

By asset's exposure, we understand that assets are more exposed to the shadow cost of funding if their returns co-move more with it. As soon as covariance increases, it is expected that possible changes in the cost of funding will have greater impact on the

\footnotetext{
${ }^{5}$ Notice that the time series intercept, in this case, is different from the pricing error, since the "TED factor" is not an excess return and it is not priced by the asset pricing model.
} 
asset's expected premium. Margin requirements also capture this idea: given a credit restricted environment (positive TED spread) higher margins predict greater impact of an increase in the TED spread over the asset's premium, since the amount of money borrowed from interbank markets to cover margin requirements will be higher, and this capital is now more expensive.

Given the model's predictions about margin requirements and asset's exposure to the funding cost, we improve our asset pricing model by incorporating two important considerations: (i) TED Betas are time-varying, so as considering TED betas constant would be a strong hypothesis; and (ii) State variables related to margin requirements may help to explain the dynamics of TED betas, since not only margin requirements may vary through time, but also across assets, as Brunnermeier and Pedersen (2009) have already mentioned. One could relate time-varying betas to the margin-based asset pricing model using the following approximation: $\beta_{t}^{T E D, i} \approx m_{t}^{i} x$. The asset pricing model is now given by:

$$
r_{t}^{e, i}=\alpha^{i}+\left(\beta^{F, i}\right)^{\top} F_{t}+\beta_{t}^{T E D, i} \mathrm{TED}_{t}+e_{t}^{i}
$$

To determine the dynamics of individual TED betas, we follow Shanken (1990) and Pastor and Stambaugh (2003) and assume that individual TED betas are a linear function of a vector of $N$ observable state variables:

$$
\beta_{t}^{T E D, i}=\xi_{0}^{i}+\xi^{i \top} Z_{t}^{i}
$$

Observable state variables, although necessarily arbitrary, must be chosen in order to possess a certain ex ante appeal. State variables related to margin requirements may help explain TED betas' dynamics.

In Hedegaard (2011), margins were usually related to asset's tail risk and volatility. That makes sense if we imagine that investors use leveraged assets as collateral for their loans, and margins will take into account the worst possible scenario for underlying assets. Given the empirical analysis, the author observed that a linear model using measures of volatility 
and extreme value could predict margin requirements for commodities in the U.S.

Given previous insight and data availability, our state variables are:

- Margin requirements on S\&P 500 futures contracts: It is expected that individual margins should respond to changes in margin requirements from a market index, and hence, individual TED betas.

- Monthly volatility: equal to the sum of squared daily stock returns.

- Value at Risk calculated using RiskMetrics ${ }^{T M}$ methodology: we assume that monthly individual stock returns follow an $\operatorname{IGARCH}(1,1)$. Given that assumption, the VaR at the end of the current month of a long position is given by

$$
\operatorname{VaR} R_{t}^{i}=z_{\alpha} \sqrt{\left(\sigma_{t+1}^{i}\right)^{2}}
$$

Where $\left(\sigma_{t+1}^{i}\right)^{2}$ is the conditional variance, estimated given the IGARCH process, and $z_{\alpha}$ is the z-score for a given $\alpha$ probability. For more details, please refer to Tsay (2010).

Both monthly volatility and the measure of VaR are relevant to understand margin requirements, since both of them are related to tail risk. Also, if we apply these two measures to the S\&P 500 index, we could compare them with the observable aggregate margin. In Figure 2, monthly volatility and VaR were estimated for the S\&P 500, and both measures seem to covary with relative margins. Both variables are also significant in a time series regression with aggregate margins as dependent variable.

\section{Figure 2 here.}

After having defined the state variables, substitute (4.7) into (4.6) to obtain

$$
r_{t}^{e, i}=\alpha^{i}+\left(\beta^{F, i}\right)^{\top} F_{t}+\xi_{0}^{i} \mathrm{TED}_{t}+\xi^{i \top}\left(Z_{t}^{i} \times \mathrm{TED}_{t}\right)+e_{t}^{i}
$$


Equation (4.9) shows that our former model, given by equation (4.5), is mispecified in the sense that it lacks interactions between the TED spread and the state variables.

As common factors, the analysis considers the Fama and French (1993) market (MKT), size (SMB) and book-to-market (HML) factor portfolios (3-Factor model).

$$
r_{t}^{e, i}=\alpha_{3 F}^{i}+\beta^{M K T, i} \mathrm{MKT}_{t}+\beta^{S M B, i} \mathrm{SMB}_{t}+\beta^{H M L, i} \mathrm{HML}_{t}+\beta_{t}^{T E D, i} \mathrm{TED}_{t}+e_{t}^{i}
$$

Estimation strategy is straightforward in the literature of empirical asset pricing tests of new factors:

1. At December of each year, we estimate equation (4.10) for each asset in a time series analysis, using 5-years prior observations on returns, factor portfolios and interactions of state variables with TED spread;

2. Using the estimated time-varying "TED betas", we rank the assets in 10 equallyweighted portfolios and analyze their monthly returns one year ahead. One important issue to take into consideration is which beta should we use to rebalance our TED related portfolios. Consider an investor that takes into account its portfolio's exposure to the TED spread. If he rebalances his portfolio every year, we could think that, at year $\tau$, he will be worried with $\tau+1$ portfolio's exposure, using past information to estimate how the portfolio's exposure on year $\tau+1$ will be.

Following previous rationale, we rebalance our 10 TED related portfolios at december of each year $\tau$ using the yearly TED beta mean from year $\tau$ :

$$
\beta_{\text {rebalancing, } \tau}^{T E D, i}=\sum_{j=\mathrm{jan}}^{\mathrm{dec}}\left(\hat{\xi}_{0}^{i}+\hat{\xi}^{i \top} Z_{j, \tau}^{i}\right) / 12
$$

3. Each year, we rebalance portfolios following steps 1 and 2 .

At the end of the procedure, we obtain historical returns of 10 TED related portfolios.

Before analysing results, it is important to understand the expected TED beta signal. Since we are using end-of-the month variables, it is expected that an increase in the 
shadow cost of funding should decrease current prices, given that it becomes even harder to finance leverage positions or eventual margin calls. Therefore, TED betas should be negative.

By this logic, portfolio number 1 should be the one that most negatively covaries with the shadow cost of funding, and portfolio number 10, the one that least negatively covaries. Co-movements are directly related to the asset's exposure to the shadow cost of funding. Estimations of post-ranking TED betas (using the 10 TED related portfolios) follow our primary predictions. Figure 3 shows the relation between post-ranking TED betas and mean portfolio returns considering the 3-Factor model. The slope coefficient is negative and significant.

Figure 3 here.

In order to perform a more robust analysis, one should check how the pricing error behaves through the TED-related portfolios. By removing the TED spread, all the remaining factors are excess returns, so alphas should capture the excess return not explained by fundamentals. We should expect not only alphas different from zero, but also that the most exposed portfolio to the TED spread should have a higher alpha than the least exposed. Table 1 shows results on alphas for the 3-Factor model (standard deviation in parentheses).

Table 1 here.

Results go in the expected direction: alphas decrease from the most exposed portfolio to the least exposed in both models. For the 3-Factor model, the most exposed portfolio pays unexplained excess returns of $5.19 \%$, against $2.57 \%$ on the least exposed. The 1-10 
strategy (going long on portfolio 1 and short on portfolio 10) pays an excess return of $2.622 \%$, controlling for their respective risk factors. It shows that part of the unexplained excess return is priced by movements in TED spread.

In addition to the discussion about the 1-10 spread, we estimate the "TED spread premium" using all ten TED-related portfolios following Pastor and Stambaugh (2003). Define the multivariate regression as

$$
r_{t}^{e}=\beta_{0}+B F_{t}+\beta^{T E D} \mathrm{TED}_{t}+e_{t}
$$

where $r_{t}^{e}$ is a $10 \times 1$ vector of annualized portfolio excess returns and $F_{t}$ is a $k \times 1$ vector containing all considered excess return factors (MKT, SMB and HML). Given specification, $B$ is a $10 \times k$ coefficient matrix, $\beta_{0}$ is a $10 \times 1$ vector of intercepts and $\beta^{T E D}$ is a $10 \times 1$ vector of coefficients related to the TED spread.

Assume that the decile portfolios are priced by their return sensitivities related to traded factors and the non-traded TED spread.

$$
E\left(r_{t}^{e}\right)=B \lambda_{F}+\beta^{T E D} \lambda_{T E D}
$$

Taking unconditional expectation on both sides of (4.12) and substituting in (4.13) gives

$$
\beta_{0}=\beta^{T E D}\left[\lambda_{T E D}-E\left(\mathrm{TED}_{t}\right)\right]
$$

Since traded factor are priced by the model, we have that $E\left[F_{t}\right]=\lambda_{F}$. The non-traded premium is not a payoff on a traded position, and therefore is not priced by the model, the reason why $\lambda_{T E D}$ may deviate from $E\left(\mathrm{TED}_{t}\right)$.

We estimate $\lambda_{T E D}$ using the Generalized Method of Moments (GMM). Define

$$
\theta=\left[\begin{array}{llll}
\lambda_{T E D} & E\left(\mathrm{TED}_{t}\right) & \left(\beta^{M}\right)^{\prime} & \operatorname{vec}(B)^{\prime}
\end{array}\right]^{\prime}
$$

as the vector of unknown parameters. The GMM estimator of $\theta$ minimizes $g(\theta)^{\prime} W g(\theta)$, 
where $g(\theta)=(1 / T) \sum_{t=1}^{T} f_{t}(\theta)$, and

$$
\begin{aligned}
& f_{t}(\theta)=\left(\begin{array}{ccc}
1 & F_{t}^{\prime} & \left.\mathrm{TED}_{t}\right)^{\prime} \otimes e_{t} \\
\mathrm{TED}_{t} & -E\left(\mathrm{TED}_{t}\right)
\end{array}\right) \\
& e_{t}=r_{t}^{e}-\beta^{M}\left[\lambda_{T E D}-E\left(\mathrm{TED}_{t}\right)\right]-B F_{t}-\beta^{T E D} \mathrm{TED}_{t}
\end{aligned}
$$

Where otimes represents the kronecker product operator. The results are reported for $E\left(\mathrm{TED}_{t}\right)$, and $\left|\lambda_{T E D}\right|$ in Table 2. For the 3-Factor model, the TED premium is negative (following prior results, since TED beta signals are negative), and is approximately significant at $90 \%$ using the weight matrix $W$ as the Identity matrix. When using the optimal weighting matrix, estimated premium is lower, but results are more significant (at 95\%).

Table 2 here.

\section{4..1.3 Size and TED spread risk}

We continue to explore how stocks react to the TED spread risk factor, and this section analizes how TED spread helps to explain asset prices for different size groups. The theoretical motivation comes from the fact that small stocks may be more vulnerable to elevated margin requirements, especially during times of financial distress. Loadings on TED spread should be higher, as they would be more exposed to funding costs.

Estimation procedure is the same as in previous section, with the difference that, before ranking assets according to their TED spread exposition, we rank portfolios first into three equally divided size groups ( - small size, M - Medium size and B - big size) and then, for each group, we rank stocks in 10 equally-weighted portfolios.

At the end of the estimation procedure, we obtain 30 post-ranking portfolios, 3 groups of 10 TED-related portfolios, and each group separated by size. Figure 4 shows the TED betas calculated on post ranking portfolios for the 30 size-TED beta portfolios, and figures 
5, 6 and 7 show for each size group. Only small stocks show a significant negative relation between mean returns and TED betas.

Figure 4 here.

Figure 5 here.

Figure 6 here.

Figure 7 here.

Table 3 presents our results obtained for the 3-Factor model. We observe that the TED risk factor is much more evident for small size stocks (1 minus 10 strategy paying excess returns of $5.89 \%$ annually, and significant at $90 \%$ ) then for medium or big size stocks (1 minus 10 alphas are negative for such groups). Only alphas from small size stocks follow our prior predictions, and fall as TED exposition reduces ${ }^{6}$. We conclude that TED risk factor is only relevant for pricing small size stocks. Financial agents may consider small size companies as riskier in terms of funding constraints, i.e. it may be more difficult to fund leverage positions on small size stocks, thus raising required premium.

\footnotetext{
${ }^{6}$ Alphas are not monotonically related to portfolio numbers, and such a relationship is difficult when dealing with empirical evidence, but still, the least exposed pays less return then the most exposed, a significant evidence of the presence of TED risk among small caps.
} 
Table 3 here.

\section{4..2 Cross Section Analysis - Constant TED Betas}

Previous evidence is quite strong to show that TED spread may be a risk factor, specially among small caps. In this section, we present a robustness analysis by which we consider "constant TED betas". The objective here is to show that our results are not only driven by movements in the state variables used to represent time-varying betas.

Return to equation (4.5) and keep TED betas constant. Thus, the 3-Factor Model is given by

$$
r_{t}^{e, i}=\alpha_{3 F}^{i}+\beta^{M K T, i} \mathrm{MKT}_{t}+\beta^{S M B, i} \mathrm{SMB}_{t}+\beta^{H M L, i} \mathrm{HML}_{t}+\beta^{T E D, i} \mathrm{TED}_{t}+e_{t}^{i}
$$

Estimation strategy is equal to the previous procedure:

1. At December of each year, we estimate equation (4.17) for each asset in a time series analysis, using 5-years prior observations on returns, factor portfolios and the TED spread;

2. Using the estimated constant "TED betas", we rank assets in 10 equally-weighted portfolios and analyze their monthly returns one year ahead.

3. Each year, we rebalance portfolios following steps 1 and 2 .

Estimations were performed for the 3-Factor model (Fama-French factors). Figure 8 shows post ranking TED betas. Betas follow previous analysis by showing a negative relation with mean returns.

Figure 8 here. 
Focusing our analysis on alphas, Table 4 reports estimation results of excess portfolio returns on excess factor returns. Results are consistent with our expectations: alphas decrease from the most exposed portfolio to the least exposed. Alphas from portfolios 1 and 2 seem to be bigger than alphas on portfolios 9 and 10 and equally weighted 1-10 spread on the 3 -Factor model is $2.774 \%$.

\section{Table 4 here.}

Notice that the extremum portfolios are not significant, but the alphas on portfolios near them are. Alphas on P9 and P2 portfolios are significant (at least at 90\%) and their difference are consistent with the "1 minus 10" strategy, paying excess returns of $0.861 \%$ annually.

We also estimate the TED premium using the 10 TED related portfolios built by using constant TED betas. Results are shown in Table 5 and they are slightly similar to previous analysis. The TED premium is higher (in absolute value) than before when considering the optimal weight matrix, but still significant (at $99 \%$ now).

\section{Table 5 here.}

Separating stocks in 3 equally divided size groups as before gives some interesting results too. Figure 9 shows TED betas calculated on post ranking portfolios for the 30 sizeTED beta portfolios, now using constant TED betas. Again, results are consistent with previous analysis.

Figure 9 here. 
Figures 10, 11 and 12 show the same relation separated for each size group. Notice that we only observe a significant negative relation to small size stocks, also consistent with previous analysis.

Figure 10 here.

Figure 11 here.

Figure 12 here.

Table 6 shows the same analysis as performed before. The TED factor seems to be stronger for small size stocks also. 1 minus 10 strategy for small size stocks now pays additional excess returns of $2.479 \%$ annually. For other size groups, results do not show presence of a TED spread premium. Only alphas from small size stocks (slightly) decrease when exposition to the TED spread decreases.

Table 6 here.

Results here are consistent with prior empirical results and contribute to intensify it: TED spread empirically constitutes a risk factor, and its impact on small size stocks is greater than on medium and big size stocks. 


\section{4..3 TED Betas and Margin Requirements}

In order to give credibility for results obtained previously, one must believe that margins are related to asset's exposure on the TED. This section brings empirical evidence of the connection between margin requirements and TED Betas.

Since we do not observe margin requirements for all stocks, we restrict our empirical analysis here to returns on the S\&P 500, since we observe margins for S\&P 500 futures. We first estimate a Multivariate GARCH BEKK(1,1) model for monthly S\&P 500 excess returns (annualized) and monthly TED spread, following Engle and Kroner (1995) methodology, to understand how TED and returns co-move. Define $\Sigma_{t}$ as their time-varying covariance matrix. Covariance structure is given by:

$$
\begin{aligned}
y_{t} & =\mu+\epsilon_{t} \\
\Sigma_{t} & =A A^{\prime}+A_{1}\left(\epsilon_{t-1} \epsilon_{t-1}^{\prime}\right) A_{1}^{\prime}+B_{1} \Sigma_{t-1} B_{1}^{\prime}
\end{aligned}
$$

Where $y_{t}$ is a $2 \times 1$ vector formed by S\&P 500 excess returns and the TED spread. $A$ is a $2 \times 2$ lower triangular positive definite matrix, $A_{1}$ and $B_{1}$ are $2 \times 2$ coefficient matrices estimated by maximum likelihood, assuming a normal distribution for the demeaned $2 \times 1$ vector $\epsilon_{t}$.

In order to obtain a more robust result, we used monthly data since January 1971 (first period where TED spread is available) until December 2010 . Results are showed in Table 7.

Table 7 here.

Estimated variance and covariance series are showed in Figure 13. We then calculate a

\footnotetext{
${ }^{7}$ The reason why cross section analysis were implemented only for data starting at April 1982 is because margin requirements on S\&P 500 futures is only available after this period, and we wanted to use the same length on both cases (constant TED betas and time-varying TED betas) in order to compare results. Nevertheless, once we expand database to start at January 1971, results for the constant case do not present significant changes.
} 
time-varying estimate of the S\&P 500 TED beta, given by $\beta_{t}^{T E D}=\operatorname{cov}_{t}\left(R_{m}, T E D\right) / \operatorname{var}_{t}(T E D)$. It is important to notice that covariance between TED spread and S\&P 500 returns is negative (following our prior results) and spikes during times of financial restrictions. Time-varying TED beta is also negative in the entire period and becomes more volatile during times of financial distress.

Figure 13 here.

Now, we compare time-varying TED betas with relative margin requirements from S\&P 500 futures contracts. Figure 14 shows monthly margin requirements for futures contracts on the S\&P 500 index (blue dashed line), available by the CME since 1982 until december 2010. During "good times", margins are relatively low, keeping levels between 4 to 5 percent. The spikes can be identified as periods of great financial distress, as in the 1987 stock exchange crash (margins reached about almost 13.3\%) and the 2007 subprime crisis (margins reached almost 13.7\%). The red solid line is the estimated time-varying TED beta using the multivariate GARCH procedure from before. Notice that they both comove, specially during times of financial distress. Correlation between both series is -0.4 , and OLS estimation of relative margins on TED Betas returns a slope coefficient of - 0.61 , significant at $99 \%$.

Figure 14 here.

Given previous evidence, it is reasonable to consider that TED betas and margin requirements may move closely, and its relation becomes even more evident in times of credit restrictions. Nonetheless, we are not properly testing whether margins are directly related to asset's co-movement with the TED spread, but showing an relevant evidence that goes in favor of such prediction. 


\section{Conclusion}

The paper analized the impact of credit restrictions on expected stock returns. We tested whether TED spread constitutes a risk factor, motivated by the fact that the spread capture an important movement in credit markets: the higher the spread, the more difficult it is for financial institutions to cover possible margin calls, or fund new portfolio acquisitions. Stocks more exposed to funding difficulties (elevated sensibility to TED spread) become less attractive and should pay an additional premium to compensate the additional funding cost.

A good candidate to explain why TED spread may be considered a risk factor is the margin-based asset pricing model of Gârleanu and Pedersen (2011). We found empirical evidence that margin requirements may co move with the asset's exposure to the TED spread, which gives us some insights: Betas on TED spread may not be constant, and they may be influenced by state variables related to margin requirements. We then applied cross section analysis using time-varying TED betas as a linear function of state variables related to margin requirements. The results found were quite in favor of the presence of the TED spread risk (controling for known risk factors), specially among small size stocks Nevertheless, we also applied cross section analysis considering constant TED betas as a robustness analysis, and found that results do not change significantly. Alphas still follow the same pattern as before. GMM estimates of the TED premium are significant (at least at $95 \%$, when considering the optimal weighting matrix), and its signal goes in the same direction as predicted.

In order to improve empirical analysis of the margin-based model, it would be necessary to have data on individual margin requirements, and we recognize this important limitation. Nonetheless, our results here were never before documented in the literature of empirical asset pricing, and could help to guide new models relating credit restrictions with expected returns. 


\section{Appendix}

\section{$6 . .1$ Figures}

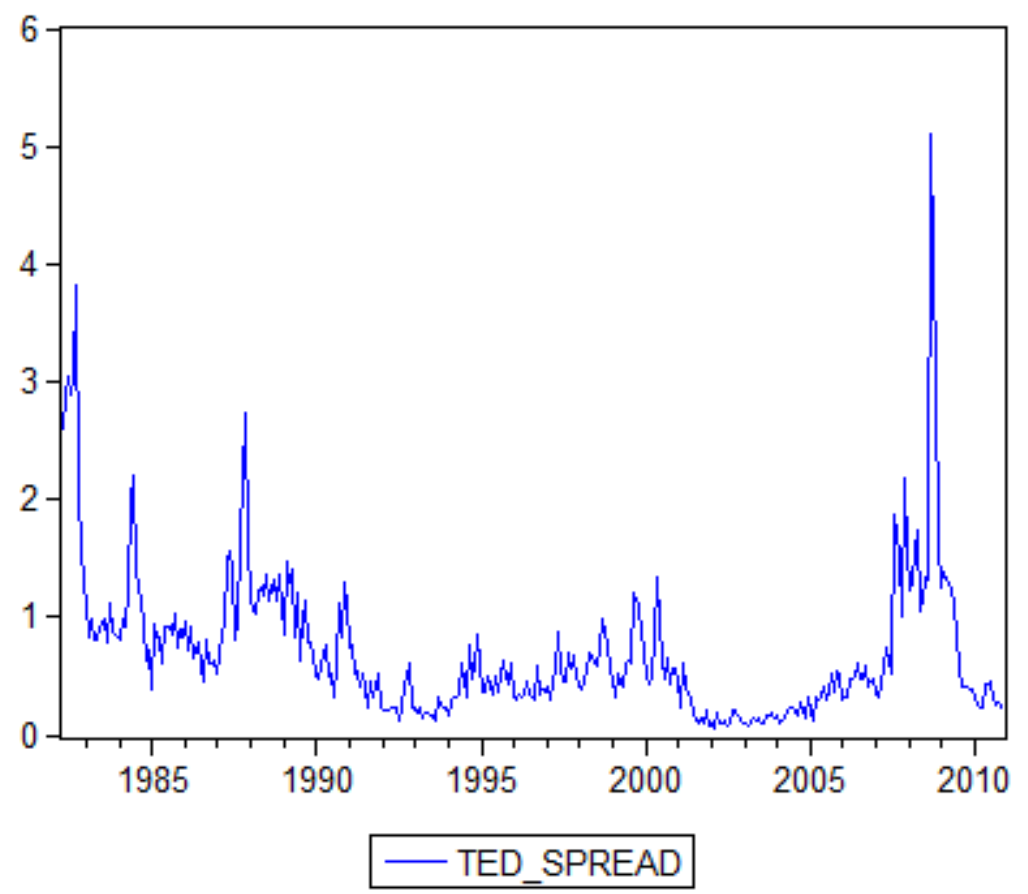

Figure 1: TED Spread in annualized rates (\%)

The TED spread represents the difference between the 3-Month LIBOR Euro-dollar bond rate and the 3-Month Treasury Bill rate. Its is widely used as a measure of credit liquidity. Spikes of the TED are related to times of credit restrictions, such as the 1987 stock market crash, the Asian currency crisis of 1997 and the 2007 financial crisis. It serves as a proxy to the shadow cost of an additional unit of funding, which is the spread between an uncollateralized debt rate and a collateralized debt rate. 

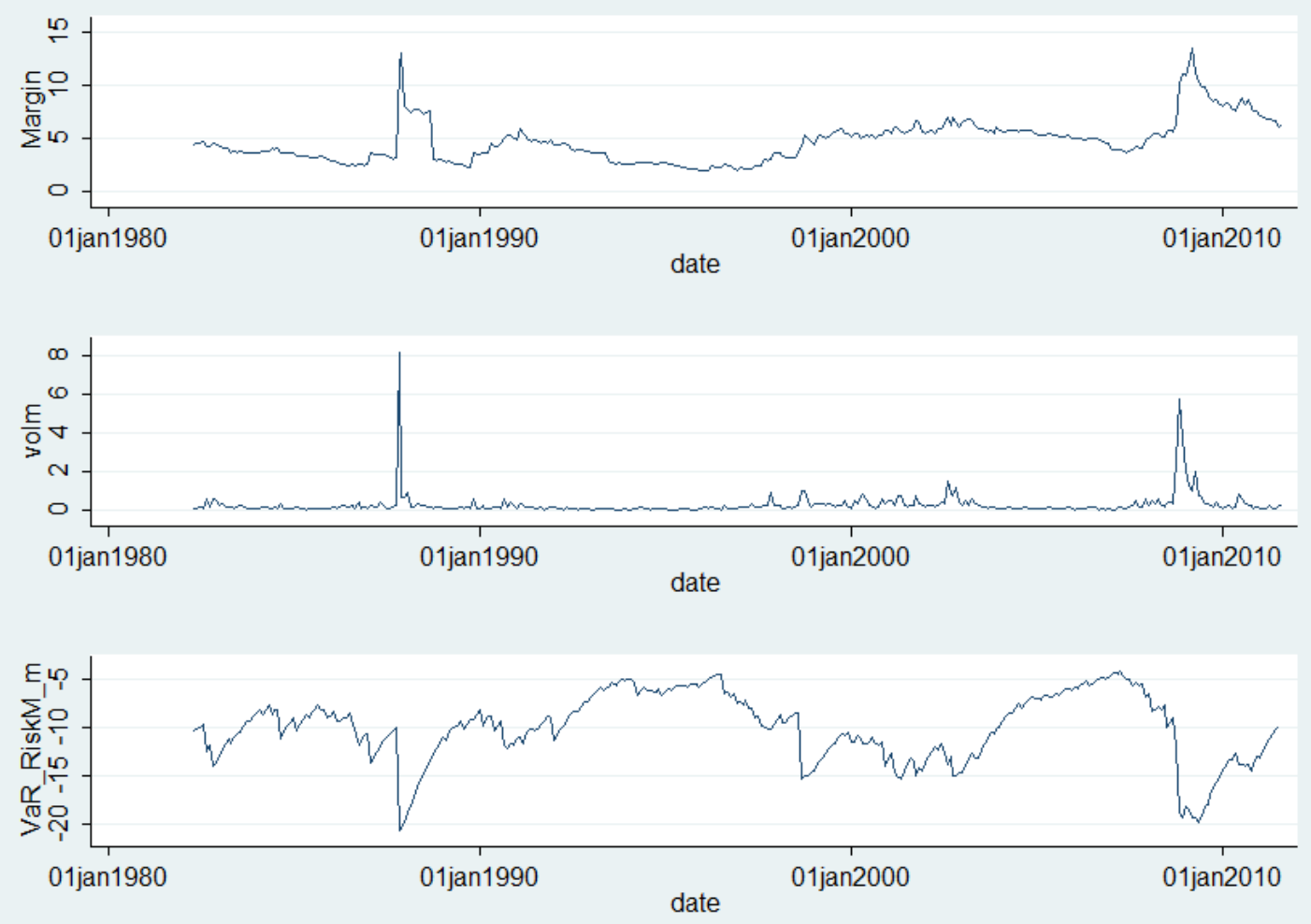

\section{Figure 2: Relative Margins (\%), Monthly volatility (Volm,\%) and VaR ( VaR_RiskM_m, \%) for S\&P 500}

Monthly volatility is calculated as the sum of squared daily returns on the S\&P 500 (dividend adjusted). Value at risk is calculated following the RiskMetrics methodology: We assume that monthly returns follow a $\operatorname{IGARCH}(1,1)$, and conditional returns are normally distributed. The amount of expected loss in $t+1$, in terms of returns, of a long position taken in $t$ is the conditional standard deviation in $t+1$ times the z-score associated with the desired probability. For this case, we assume $p=0.05$, although it will not make a difference which probability is used, since slope coefficients will capture any magnitude changes. 


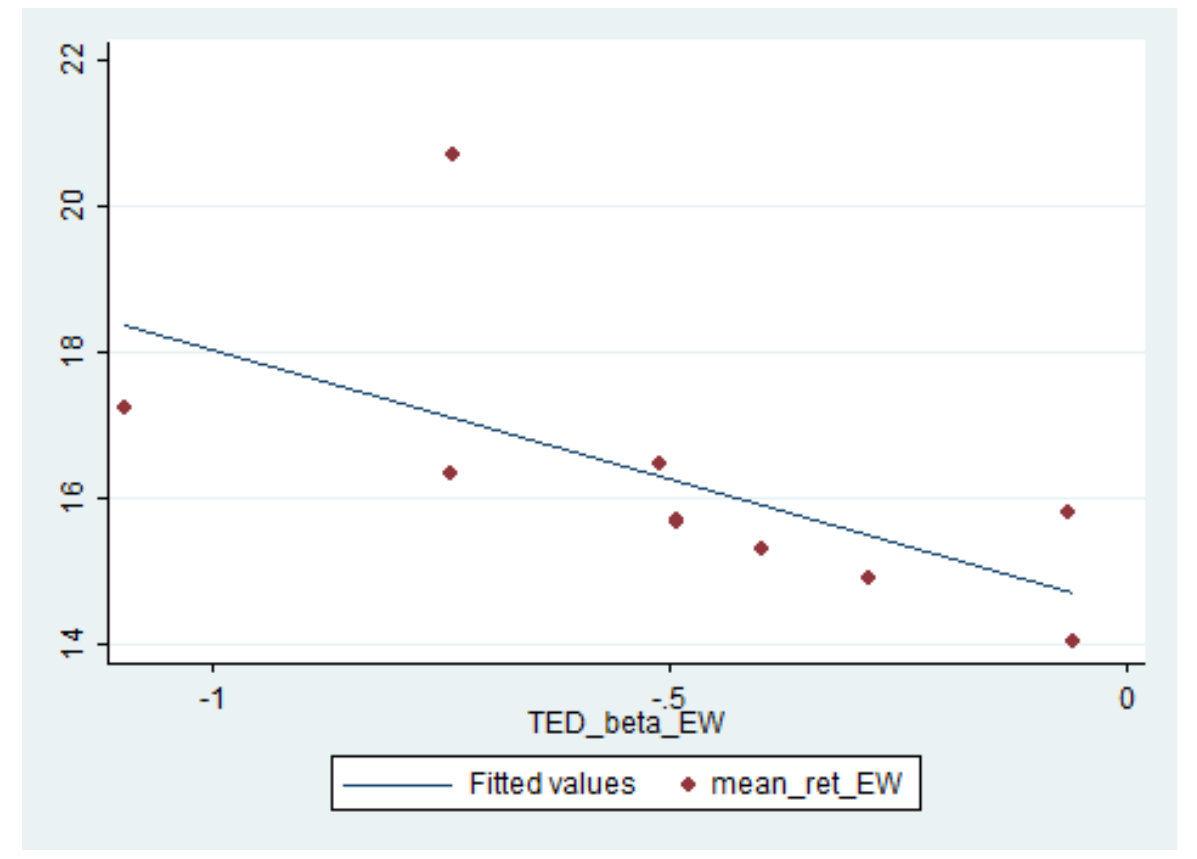

Figure 3: Post-ranking TED betas and annualized average returns (\%) from portfolios sorted on time-varying TED betas - 3-Factor model

Estimates of post-ranking betas were calculated using time series regressions with the 3 factors plus the TED spread. The negative relation between mean portfolio returns and post ranking betas is expected according our predictions. Since the time series regressions use current returns as dependent variables, end-of-the-month prices should respond negatively against an increase in the cost of funding. The negative relation with post ranking TED betas shows that more exposure to the shadow cost of funding pays more average returns. 


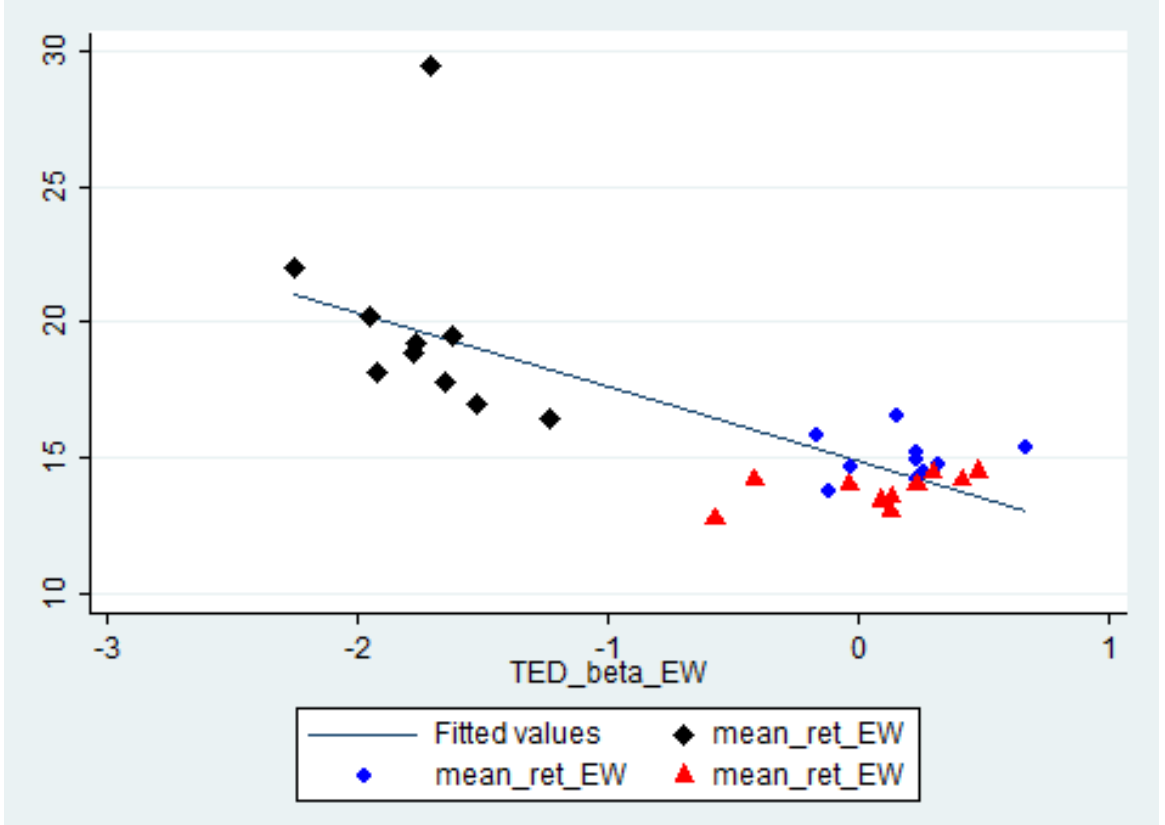

Figure 4: Post-ranking TED betas and annualized average returns (\%) for 30 size-TED portfolios built using time-varying betas - 3 Factor model

The negative relation between mean portfolio returns and post ranking betas is expected according our predictions. Since the time series regressions use current returns as dependent variables, end-of-the-month prices should respond negatively against an increase in the cost of funding. The negative relation with post ranking TED betas shows that more exposure to the shadow cost of funding pays more average returns.

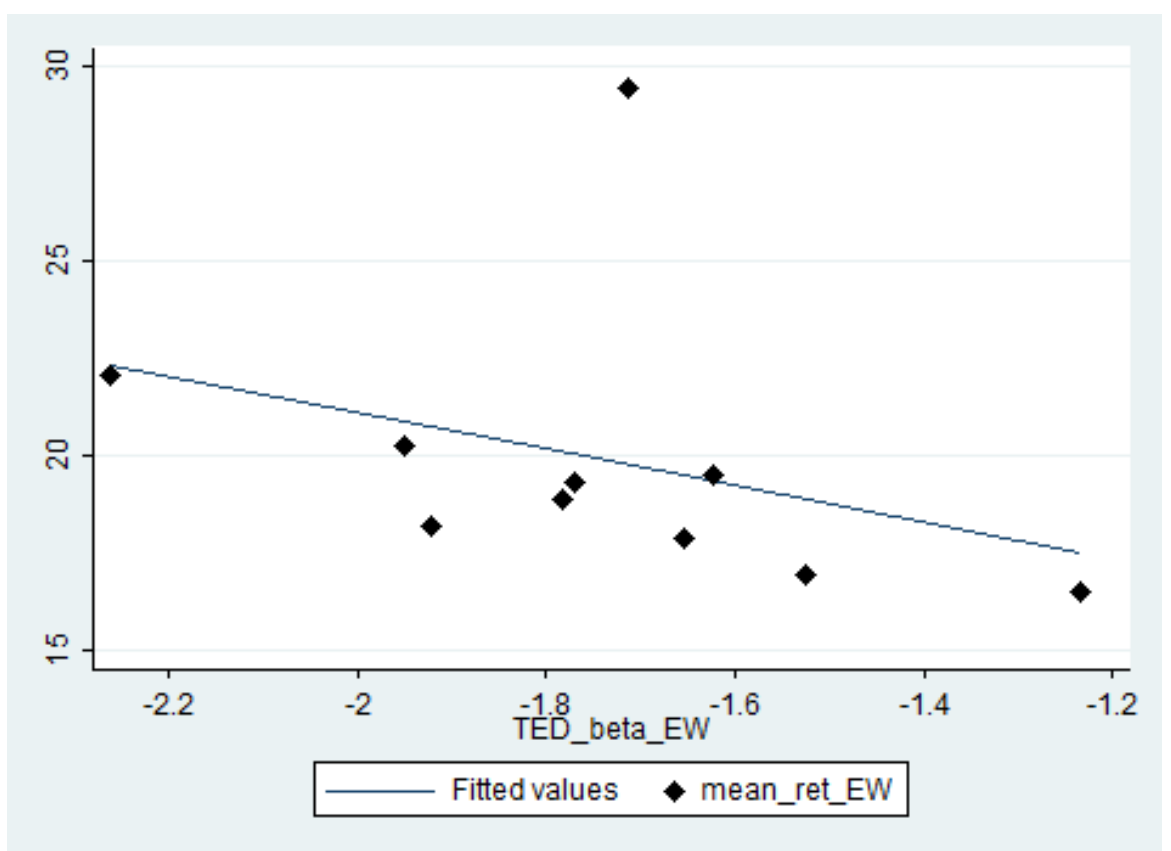

Figure 5: Post-ranking TED betas and annualized average returns (\%) for 10 size-TED portfolios built using time-varying betas: small size 


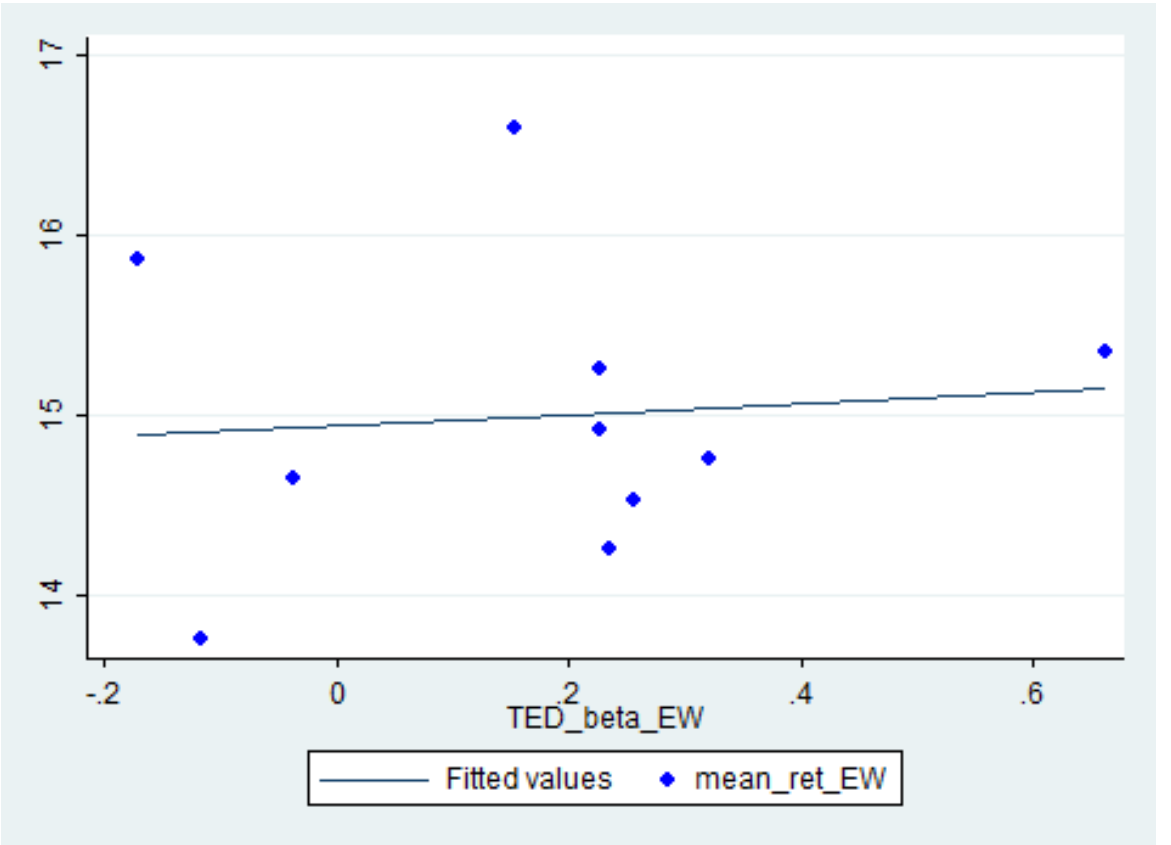

Figure 6: Post-ranking TED betas and annualized average returns (\%) for 10 size-TED portfolios built using time-varying betas: medium size

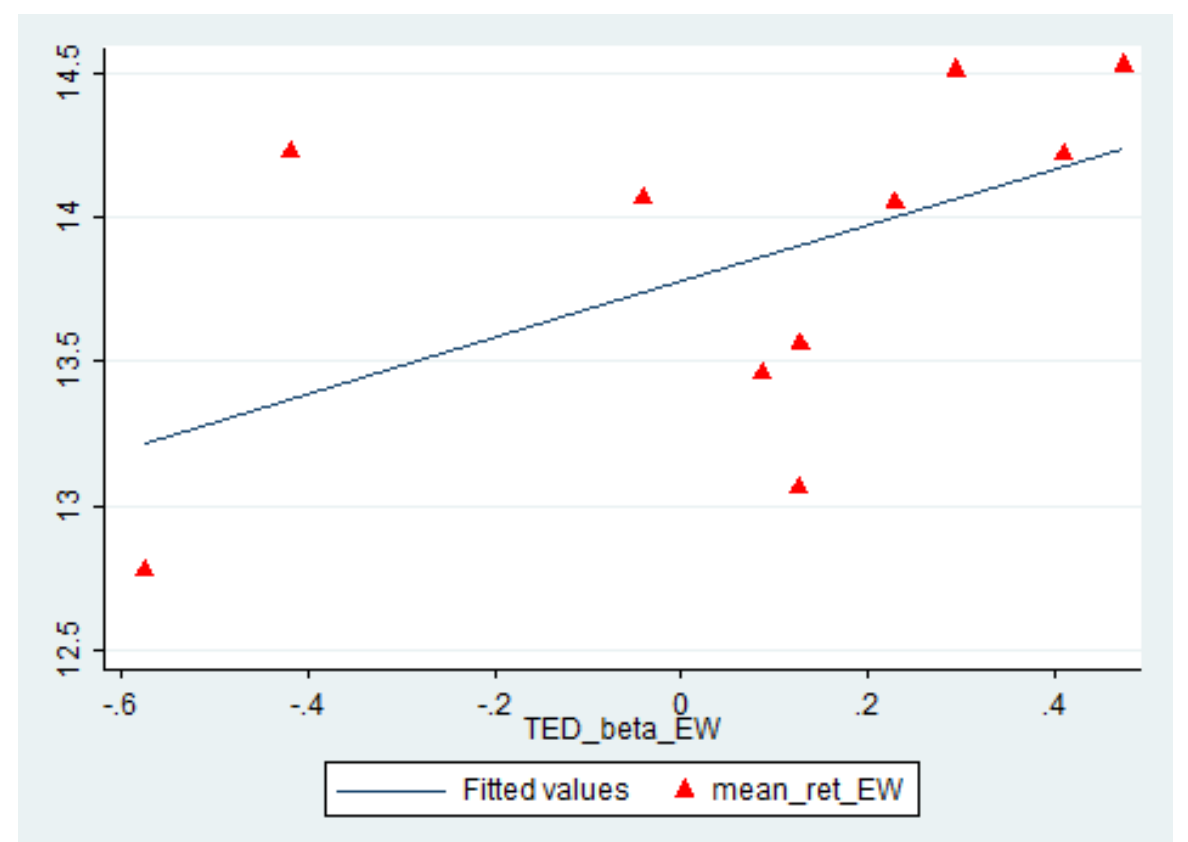

Figure 7: Post-ranking TED betas and annualized average returns (\%) for 10 size-TED portfolios built using time-varying betas: big size 


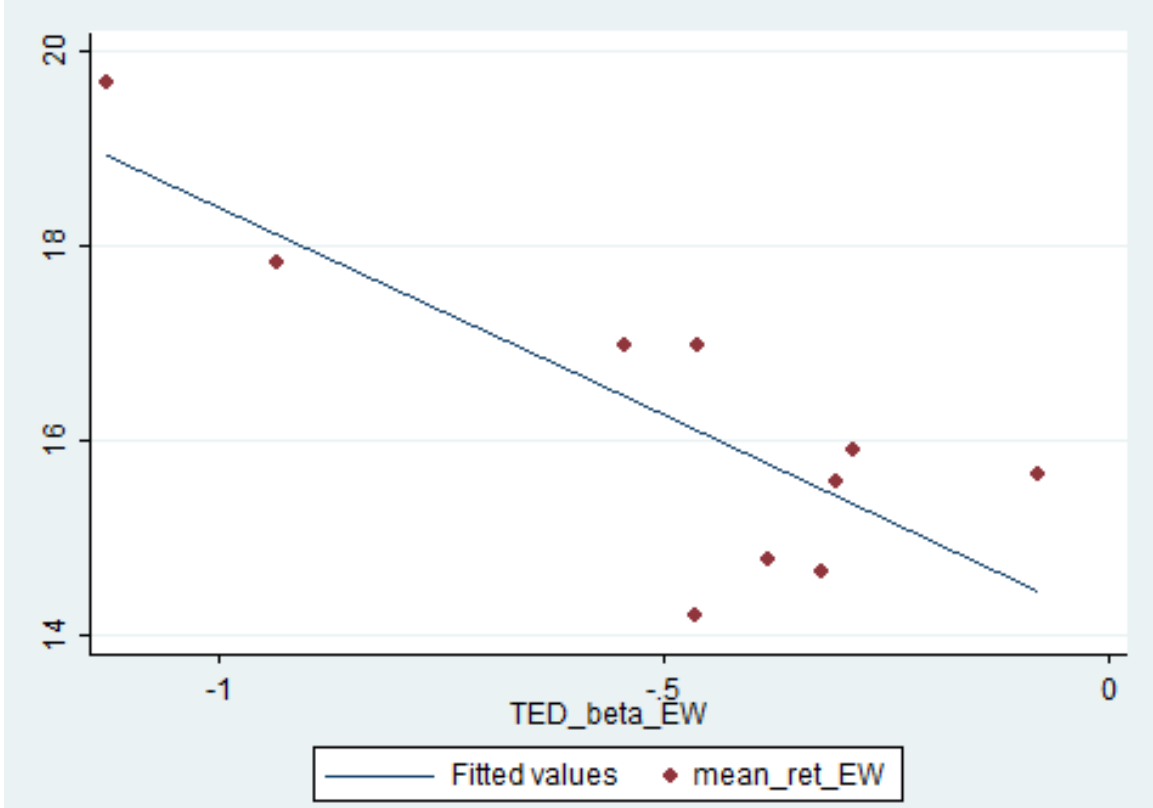

Figure 8: Post-ranking TED betas and annualized average returns (\%) from portfolios sorted on constant TED betas - 3-Factor model

Once we let margin betas to be constant through time, the negative relation continues to exist. Estimates of post ranking betas were calculated using time series regressions with the 3 factors plus the TED spread. 


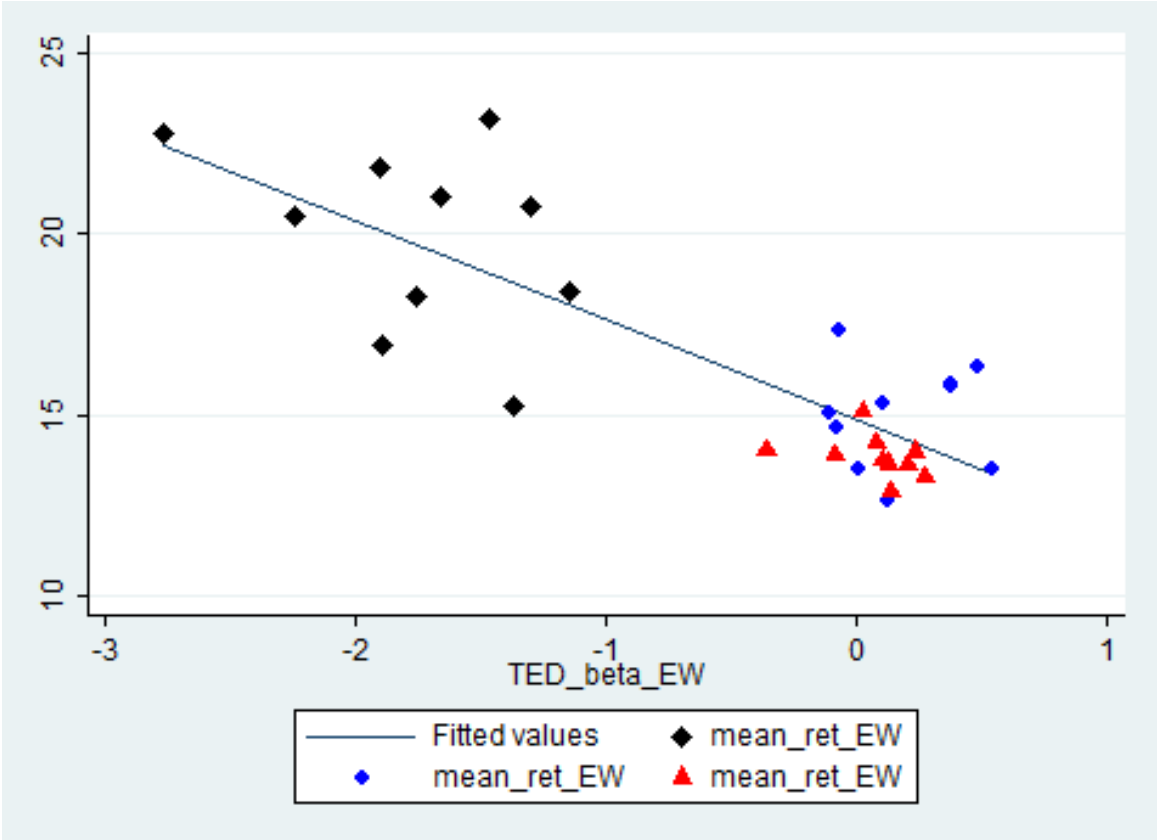

Figure 9: Post-ranking TED betas and annualized average returns (\%) for 30 size-TED portfolios built using Constant Betas - 3-Factor model

The negative relation between mean portfolio returns and post ranking betas is expected according our predictions. Since the time series regressions use current returns as dependent variables, end-of-the-month prices should respond negatively against an increase in the cost of funding. The negative relation with post ranking TED betas shows that more exposure to the shadow cost of funding pays more average returns.

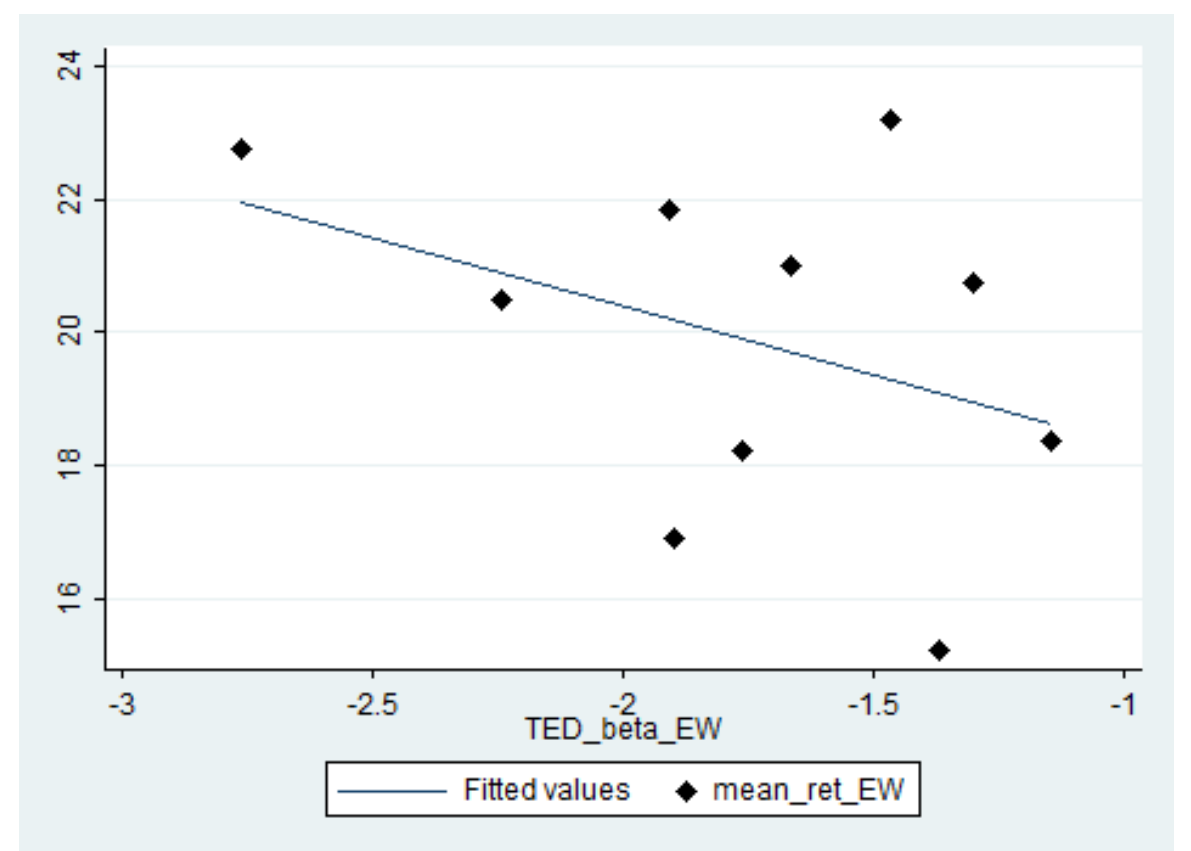

Figure 10: Post-ranking TED betas and annualized average returns (\%) for 10 size-TED portfolios built using Constant Betas: small size 


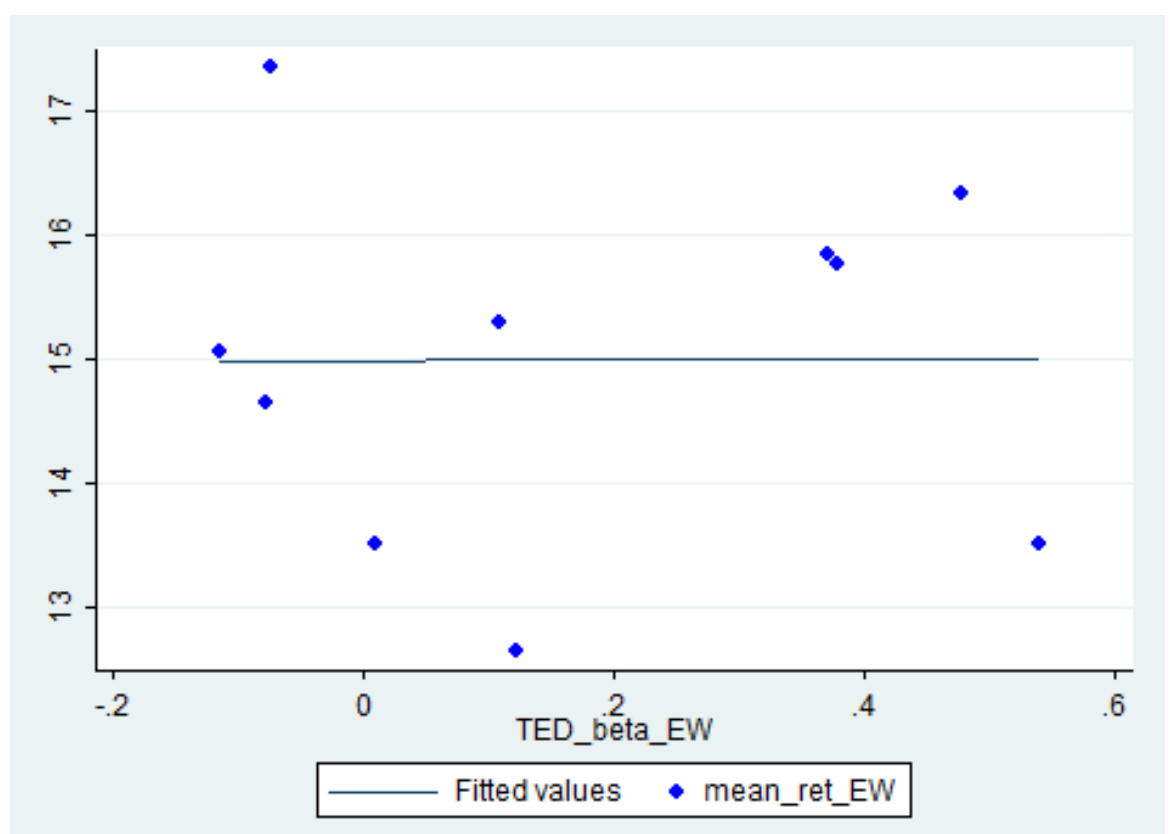

Figure 11: Post-ranking TED betas and annualized average returns (\%) for 10 size-TED portfolios built using Constant Betas: medium size

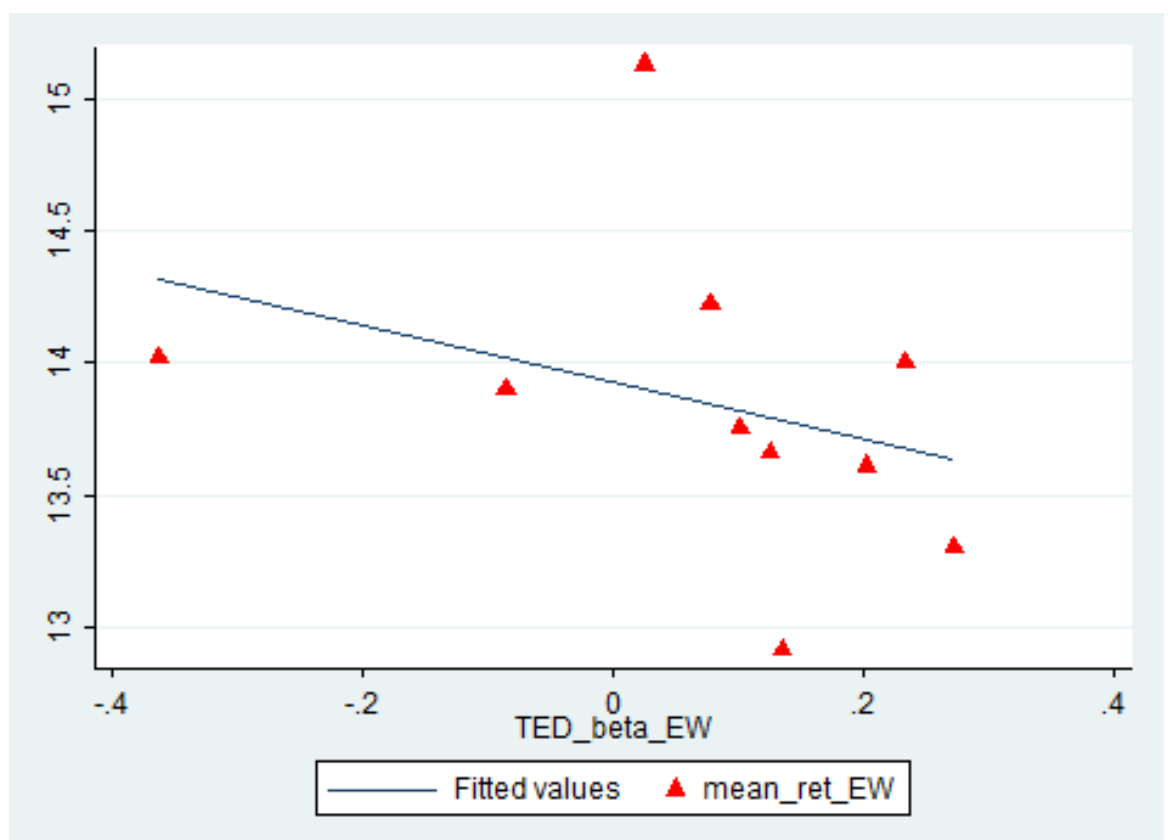

Figure 12: Post-ranking TED betas and annualized average returns (\%) for 10 size-TED portfolios built using Constant Betas: big size 
a) variance(TED)

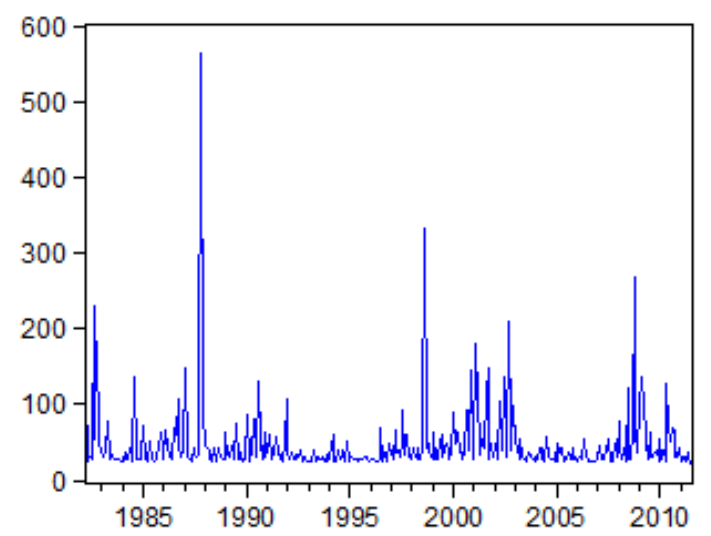

c) Covariance(S\&P returns, TED)

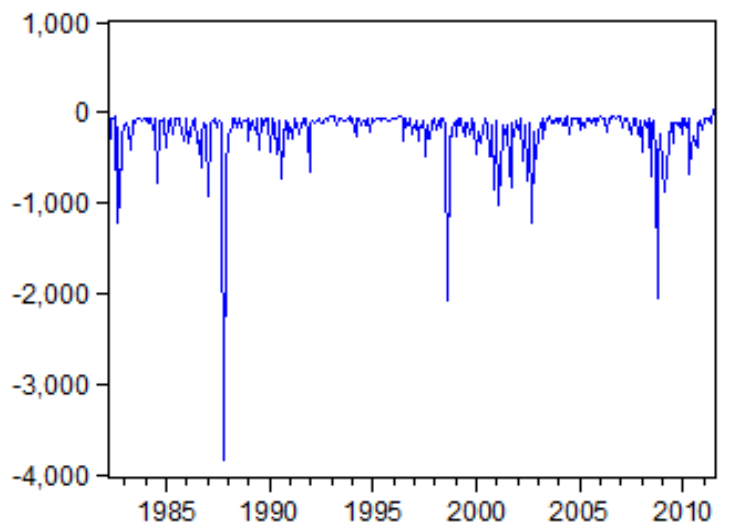

b) variance(S\&P 500 return)
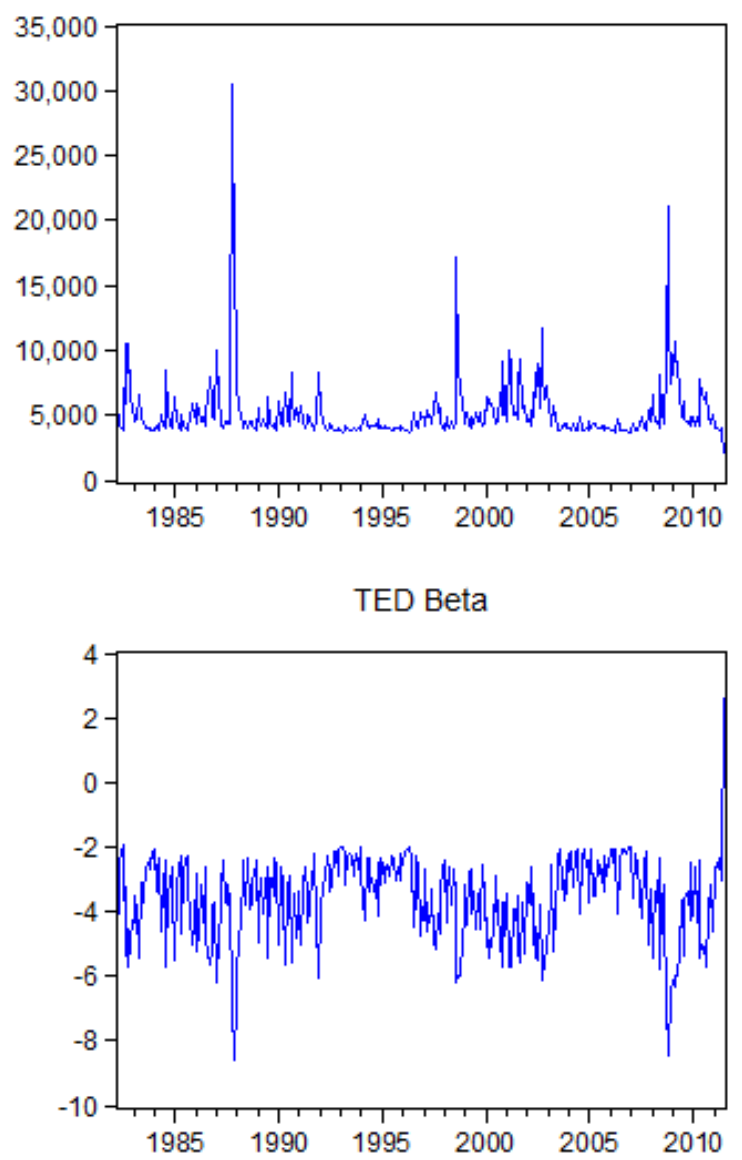

Figure 13: Estimated Variance and Covariance from prior $\operatorname{BEKK}(\mathbf{1}, \mathbf{1})$ model

Panel a) returns estimated variance series of the TED spread; Panel b) returns estimated variance series of S\&P 500 annualized returns; Panel c) returns estimated covariance series between TED spread and S\&P returns; Panel d) returns estimated time varying TED beta, which is equal to the covariance between TED and returns divided by TED spread variance. 


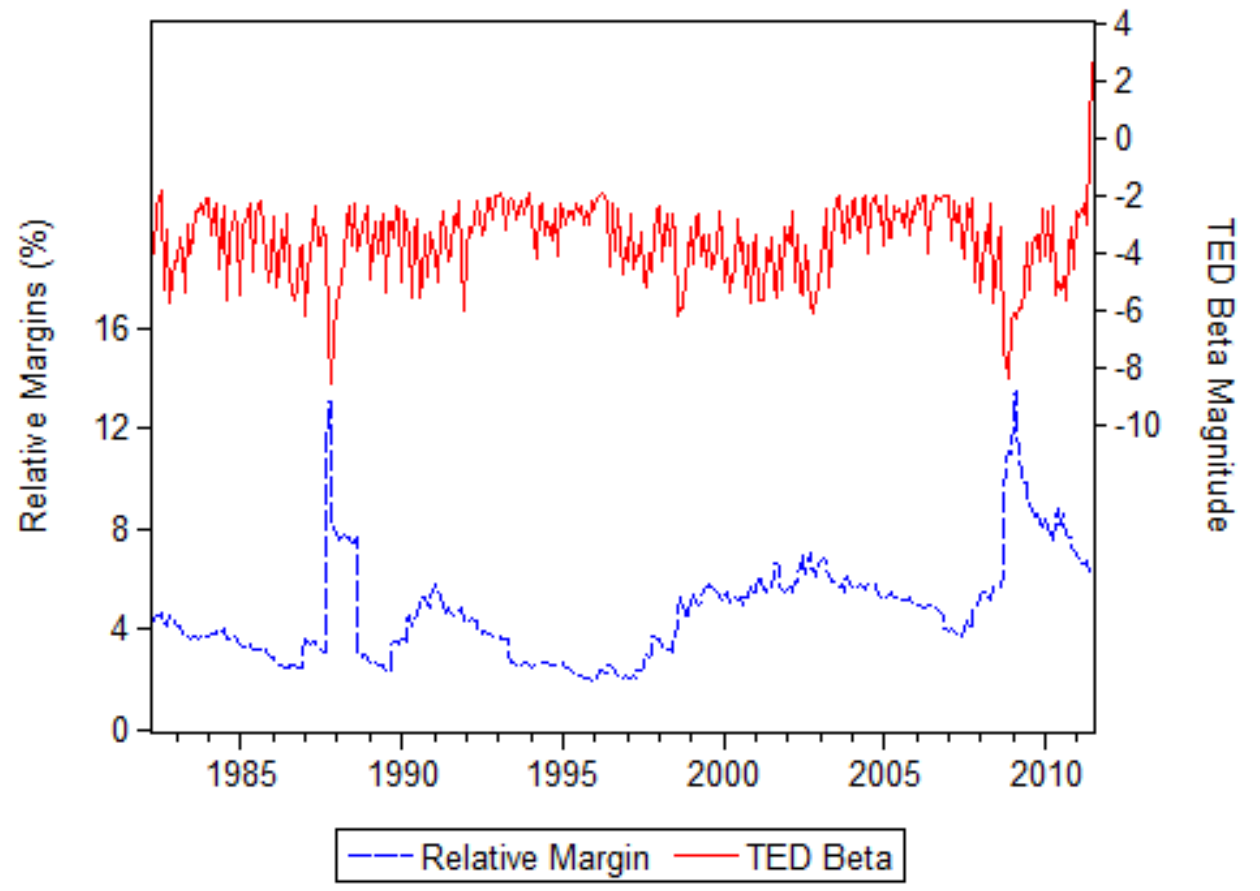

Figure 14: Relative margin requirements for futures contracts on the S\&P 500 index $(\%)$

Blue dashed line is monthly data on relative margin requirements for futures on the S\&P 500 index, obtained in the Chicago Mercantile Exchange (CME). Red solid line is estimated time-varying TED beta. 


\section{$6 . .2$ Tables}

\begin{tabular}{|c|c|c|c|c|c|c|c|c|c|c|}
\hline & \multicolumn{10}{|c|}{ Alpha Analysis: 3-Factor Model } \\
\hline & $\mathrm{P} 1$ & $\mathrm{P} 2$ & P3 & $\mathrm{P} 4$ & $\mathrm{P} 5$ & $\mathrm{P} 6$ & P7 & P8 & P9 & P10 \\
\hline$\alpha_{3 F}$ & $\begin{array}{l}5.198^{*} \\
(2.951)\end{array}$ & $\begin{array}{c}2.610 \\
(1.791)\end{array}$ & $\begin{array}{c}2.135 \\
(1.357)\end{array}$ & $\begin{array}{c}2.985^{* *} \\
(1.215)\end{array}$ & $\begin{array}{c}2.293^{* *} \\
(1.005)\end{array}$ & $\begin{array}{c}1.476 \\
(1.052)\end{array}$ & $\begin{array}{c}2.774^{* * *} \\
(1.035)\end{array}$ & $\begin{array}{c}2.624^{* *} \\
(1.066)\end{array}$ & $\begin{array}{c}2.753^{* *} \\
(1.359)\end{array}$ & $\begin{array}{c}2.576 \\
(2.078)\end{array}$ \\
\hline & $\mathrm{P} 1-\mathrm{P} 10$ & & & & & & & & & \\
\hline$\alpha_{3 F}$ & $\begin{array}{l}2.622 \\
(2.204)\end{array}$ & & & & & & & & & \\
\hline
\end{tabular}

Sta* p-value $<0.01,{ }^{* *}$ p-value $<0.05,{ }^{*}$ p-value $<0.1$

Table 1: Alphas on 10 post ranking portfolios - Time-varying Betas.

At december of each year, we estimate time series regressions for each asset using 5 years prior observations on returns, factor portfolios and TED spread. Using the estimated TED betas, we rank assets in 10 equally-weighted portfolios and analyze their monthly returns one year ahead. Each december, portfolios are rebalanced, and at the end of our sample, we have historical returns of 10 TED spread related portfolios. Given that TED betas vary through time, we use the yearly TED beta mean from year $t$ to rebalance portfolios. Eligible stocks are defined as ordinary shares traded in NYSE, AMEX and NASDAQ. Alphas are estimated as intercepts from the time series regression of excess portfolio post-ranking returns on excess return factors: the three Fama-French factors (3F). Alphas from 1-10 strategy portfolios (long on P1 and short on P10) are also calculated. Results are reported for annualized rates. 


\begin{tabular}{|c|c|c|c|}
\hline \multicolumn{4}{|c|}{ GMM Analysis: Identity Weight Matrix } \\
\hline & Coef. & std. error & t-stat \\
\hline$\lambda_{T E D}$ & -0.39462 & 0.25060 & -1.57467 \\
\hline$E\left(\mathrm{TED}_{t}\right)$ & 0.60746 & 0.04403 & 13.79635 \\
\hline \multicolumn{4}{|c|}{ GMM Analysis: Optimal Weight Matrix } \\
\hline & Coef & std. error & t-stat \\
\hline$\lambda_{T E D}$ & -0.17252 & 0.08426 & -2.04745 \\
\hline$E\left(\mathrm{TED}_{t}\right)$ & 0.55234 & 0.03880 & 14.23623 \\
\hline
\end{tabular}

Table 2: GMM estimates of TED premium and expected TED spread using time-varying sorted portfolios

Weight matrix can be identity or the optimal matrix. Results are reported only for the TED premium and the expected TED spread. Newey-West covariance matrix is used considering 1 lag. The TED premium has a negative signal, which goes in the direction of prior results, since TED betas are negative. 


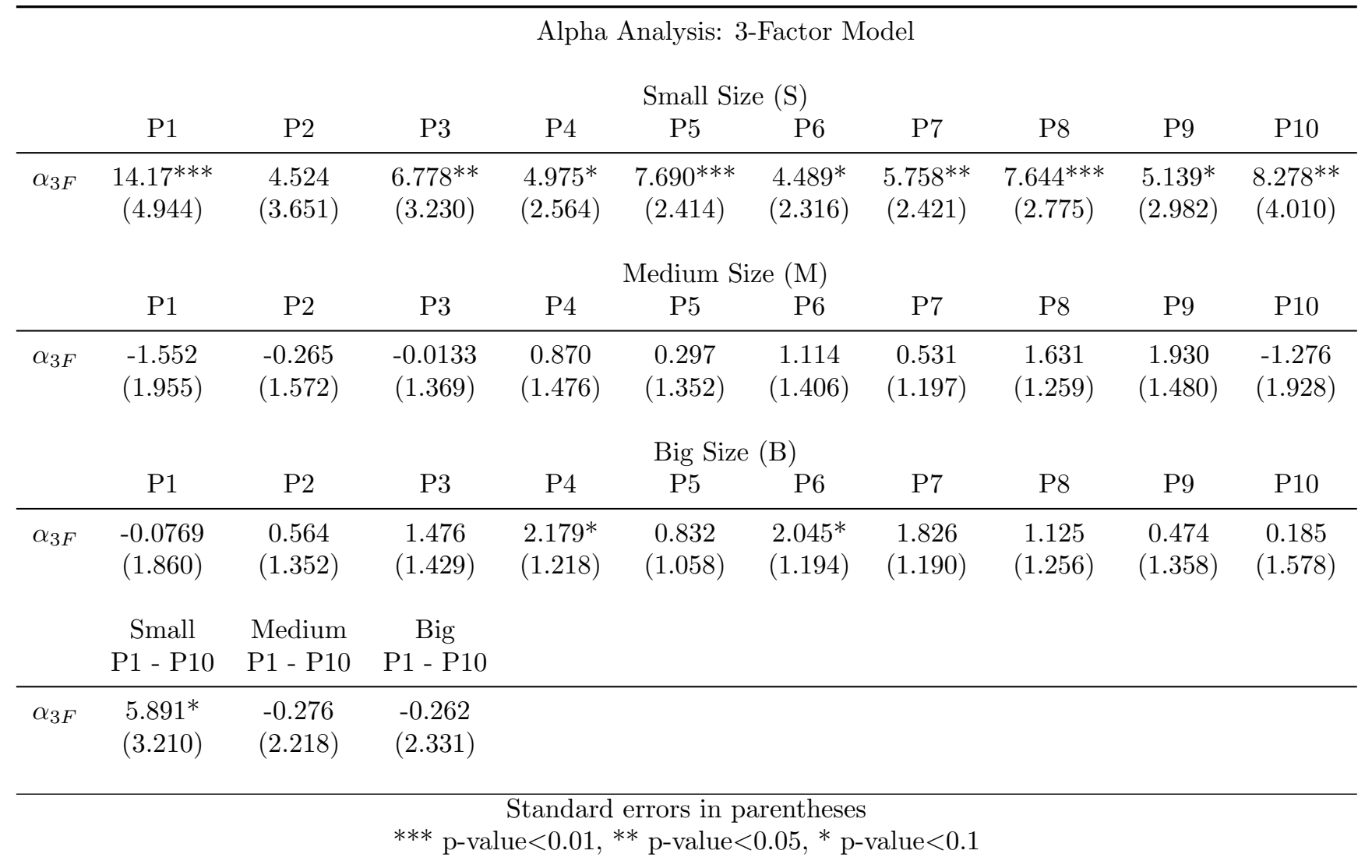

Table 3: Alphas on 10 post ranking portfolios divided by size groups.

At december of each year, we estimate time series regressions for each asset using 5 years prior observations on returns, factor portfolios and TED spread. After TED Beta estimations, we first equally divide stocks into three size groups: stocks with small size (S), stocks with medium size (M) and stocks with big size (B). For each size group, using the estimated TED betas, we rank assets in 10 equally-weighted portfolios and analyze their monthly returns one year ahead. Each december, portfolios are rebalanced, and at the end of our sample, we have historical returns of 30 TED spread related portfolios, 10 for each size group. Given that TED betas vary through time, we use the yearly TED beta mean from year $t$ to rebalance portfolios. Eligible stocks are defined as ordinary shares traded in NYSE, AMEX and NASDAQ. Alphas are estimated as intercepts from the time series regression of excess portfolio post-ranking returns on excess return factors for the three Fama-French factors (3F). Alphas from 1-10 strategy portfolios (long on P1 and short on P10) are also calculated. Results are reported for annualized rates. 


\begin{tabular}{|c|c|c|c|c|c|c|c|c|c|c|}
\hline & \multicolumn{10}{|c|}{ Alpha Analysis: 3-Factor Model } \\
\hline & P1 & $\mathrm{P} 2$ & P3 & $\mathrm{P} 4$ & P5 & P6 & $\mathrm{P} 7$ & P8 & P9 & $\mathrm{P} 10$ \\
\hline$\alpha_{3 F}$ & $\begin{array}{c}4.840 \\
(3.313)\end{array}$ & $\begin{array}{l}3.512^{*} \\
(1.848)\end{array}$ & $\begin{array}{l}3.508^{* *} \\
(1.468)\end{array}$ & $\begin{array}{c}1.511 \\
(1.118)\end{array}$ & $\begin{array}{c}1.514 \\
(1.224)\end{array}$ & $\begin{array}{r}2.288^{* *} \\
(1.089)\end{array}$ & $\begin{array}{c}2.777^{* * * *} \\
(0.972)\end{array}$ & $\begin{array}{c}2.782^{* *} \\
(1.110)\end{array}$ & $\begin{array}{l}2.651^{* *} \\
(1.079)\end{array}$ & $\begin{array}{c}2.066 \\
(1.955)\end{array}$ \\
\hline & $\mathrm{P} 1$ - P10 & & & & & & & & & \\
\hline$\alpha_{3 F}$ & $\begin{array}{c}2.774 \\
(3.100)\end{array}$ & & & & & & & & & \\
\hline
\end{tabular}

\author{
Standard errors in parentheses \\ $* * *$ p-value $<0.01,{ }^{* *}$ p-value $<0.05,{ }^{*}$ p-value $<0.1$
}

\title{
Table 4: Alphas on 10 post ranking portfolios - Constant Betas
}

At december of each year, we estimate time series regressions for each asset using 5 years prior observations on returns, factor portfolios and TED spread. Using the estimated TED betas, we rank assets in 10 equally-weighted portfolios and analyze their monthly returns one year ahead. Each december, portfolios are rebalanced, and at the end of our sample, we have historical returns of 10 TED spread related portfolios. Eligible stocks are defined as ordinary shares traded in NYSE, AMEX and NASDAQ. Alphas are estimated as intercepts from the time series regression of excess portfolio post-ranking returns on excess return factors: the three Fama-French factors (3F). Alphas from 1-10 strategy portfolios (long on P1 and short on P10) are also calculated. Results are reported for annualized rates. 


\begin{tabular}{|c|c|c|c|}
\hline \multicolumn{4}{|c|}{ GMM Analysis: Identity Weight Matrix } \\
\hline & Coef. & std. error & t-stat \\
\hline$\lambda_{T E D}$ & -0.41812 & 0.23686 & -1.76524 \\
\hline$E\left(\mathrm{TED}_{t}\right)$ & 0.56465 & 0.04402 & 12.82572 \\
\hline \multicolumn{4}{|c|}{ GMM Analysis: Optimal Weight Matrix } \\
\hline & Coef. & std. error & t-stat \\
\hline$\lambda_{T E D}$ & -0.28570 & 0.09555 & -2.98990 \\
\hline$E\left(\mathrm{TED}_{t}\right)$ & 0.52891 & 0.03599 & 14.69451 \\
\hline
\end{tabular}

Table 5: GMM estimates of TED premium and expected TED spread - 10 Expost Portfolios built using Constant Betas

Weight matrix can be identity or the optimal matrix. Results are reported only for the TED premium and the expected TED spread. Newey-West covariance matrix is used considering 1 lag. The TED premium has a negative signal, which goes in the direction of prior results, since TED betas are negative. 


\begin{tabular}{|c|c|c|c|c|c|c|c|c|c|c|}
\hline & \multicolumn{10}{|c|}{ Alpha Analysis: 3-Factor Model } \\
\hline & \multicolumn{10}{|c|}{ Small Size (S) } \\
\hline & $\mathrm{P} 1$ & $\mathrm{P} 2$ & P3 & $\mathrm{P} 4$ & P5 & P6 & P7 & P8 & P9 & $\mathrm{P} 10$ \\
\hline \multirow[t]{3}{*}{$\alpha_{3 F}$} & $\begin{array}{l}9.012^{*} \\
(5.028)\end{array}$ & $\begin{array}{c}9.052^{* *} \\
(4.146)\end{array}$ & $\begin{array}{c}7.737^{* *} \\
(3.077)\end{array}$ & $\begin{array}{c}7.735^{* * *} \\
(2.752)\end{array}$ & $\begin{array}{c}3.493 \\
(2.409)\end{array}$ & $\begin{array}{c}6.585^{* *} \\
(2.576)\end{array}$ & $\begin{array}{c}6.037^{* *} \\
(2.542)\end{array}$ & $\begin{array}{l}4.526^{*} \\
(2.405)\end{array}$ & $\begin{array}{c}8.768^{* * *} \\
(3.121)\end{array}$ & $\begin{array}{l}6.533^{*} \\
(3.845)\end{array}$ \\
\hline & \multicolumn{10}{|c|}{ Medium Size (M) } \\
\hline & $\mathrm{P} 1$ & $\mathrm{P} 2$ & P3 & $\mathrm{P} 4$ & P5 & P6 & P7 & $\mathrm{P} 8$ & P9 & $\mathrm{P} 10$ \\
\hline \multirow[t]{3}{*}{$\alpha_{3 F}$} & $\begin{array}{l}-3.420 \\
(2.139)\end{array}$ & $\begin{array}{c}1.449 \\
(1.700)\end{array}$ & $\begin{array}{c}0.184 \\
(1.319)\end{array}$ & $\begin{array}{c}-0.362 \\
(1.261)\end{array}$ & $\begin{array}{c}0.732 \\
(1.267)\end{array}$ & $\begin{array}{c}1.941 \\
(1.269)\end{array}$ & $\begin{array}{c}1.948 \\
(1.254)\end{array}$ & $\begin{array}{c}2.368 \\
(1.465)\end{array}$ & $\begin{array}{c}1.409 \\
(1.400)\end{array}$ & $\begin{array}{l}-2.948 \\
(2.022)\end{array}$ \\
\hline & \multicolumn{10}{|c|}{ Big Size (B) } \\
\hline & $\mathrm{P} 1$ & $\mathrm{P} 2$ & P3 & $\mathrm{P} 4$ & P5 & $\mathrm{P} 6$ & P7 & P8 & P9 & $\mathrm{P} 10$ \\
\hline \multirow[t]{2}{*}{$\alpha_{3 F}$} & $\begin{array}{c}0.438 \\
(1.918)\end{array}$ & $\begin{array}{c}0.744 \\
(1.465)\end{array}$ & $\begin{array}{c}0.496 \\
(1.324)\end{array}$ & $\begin{array}{c}0.434 \\
(1.310)\end{array}$ & $\begin{array}{c}1.409 \\
(1.258)\end{array}$ & $\begin{array}{c}1.273 \\
(1.104)\end{array}$ & $\begin{array}{c}1.830 \\
(1.192)\end{array}$ & $\begin{array}{c}1.747 \\
(1.229)\end{array}$ & $\begin{array}{c}1.898 \\
(1.291)\end{array}$ & $\begin{array}{c}0.458 \\
(1.676)\end{array}$ \\
\hline & $\begin{array}{c}\text { Small } \\
\text { P1 - P10 }\end{array}$ & $\begin{array}{c}\text { Medium } \\
\text { P1 - P10 }\end{array}$ & $\begin{array}{c}\text { Big } \\
\text { P1 - P10 }\end{array}$ & & & & & & & \\
\hline$\alpha_{3 F}$ & $\begin{array}{c}2.479 \\
(4.118)\end{array}$ & $\begin{array}{l}-0.472 \\
(2.428)\end{array}$ & $\begin{array}{l}-0.0202 \\
(2.634)\end{array}$ & & & & & & & \\
\hline
\end{tabular}

Table 6: Alphas on 10 post ranking portfolios divided by size groups - Constant Betas

At december of each year, we estimate time series regressions for each asset using 5 years prior observations on returns, factor portfolios and TED spread. After TED Beta estimations, we first equally divide stocks into three size groups: stocks with small size (S), stocks with medium size (M) and stocks with big size (B). For each size group, using the estimated TED betas, we rank assets in 10 equally-weighted portfolios and analyze their monthly returns one year ahead. Each december, portfolios are rebalanced, and at the end of our sample, we have historical returns of 30 TED spread related portfolios, 10 for each size group. Eligible stocks are defined as ordinary shares traded in NYSE, AMEX and NASDAQ. Alphas are estimated as intercepts from the time series regression of excess portfolio post-ranking returns on excess return factors only for the three Fama-French factors (3F). Alphas from 1-10 strategy portfolios (long on P1 and short on P10) are also calculated. Results are reported for annualized rates. 


\begin{tabular}{lccc}
\hline Estimated Coefficients & Value & Std. Error & t-stat \\
\hline$\mu_{R E T}$ & 37.098 & 2.4941 & 14.874 \\
$\mu_{T E D}$ & 1.049 & 0.046 & 22.700 \\
$\mathrm{~A}(1,1)$ & 43.562 & 8.248 & 5.281 \\
$\mathrm{~A}(2,1)$ & 1.178 & 0.403 & 2.921 \\
$\mathrm{~A}(2,2)$ & -4.234 & 0.193 & -21.895 \\
$\mathrm{~A} 1(1,1)$ & -0.544 & 0.183 & -2.981 \\
$\mathrm{~A} 1(1,2)$ & 0.356 & 0.923 & 0.386 \\
$\mathrm{~A} 1(2,1)$ & 0.081 & 0.015 & 5.614 \\
$\mathrm{~A} 1(2,2)$ & 0.967 & 0.476 & 2.030 \\
$\mathrm{~B} 1(1,1)$ & 0.707 & 0.053 & 13.318 \\
$\mathrm{~B} 1(1,2)$ & 1.000 & 0.938 & 1.066 \\
$\mathrm{~B} 1(2,1)$ & -0.040 & 0.007 & -5.757 \\
$\mathrm{~B} 1(2,2)$ & -0.175 & 0.046 & -3.802 \\
\hline Loglikelihood: $-3.9877 \mathrm{e}+3$ & & \\
\hline
\end{tabular}

Table 7: BEKK $(1,1)$ model for TED spread and S\&P 500 excess returns

We estimate a unrestricted full BEKK(1,1) model for TED spread (annualized) and current S\&P 500 monthly excess returns (annualized), both available at the FRED database. BEKK(1,1) considers the following covariance structure:

$y_{t}=\mu+\epsilon_{t}$

$\Sigma_{t}=A A^{\prime}+A_{1}\left(\epsilon_{t-1} \epsilon_{t-1}^{\prime}\right) A_{1}^{\prime}+B_{1} \Sigma_{t-1} B_{1}^{\prime}$

Where $y_{t}$ is a $2 x 1$ vector formed by $\mathrm{S} \& \mathrm{P} 500$ returns and the TED spread. $A$ is a $2 x 2$ lower triangular positive definite matrix, $A_{1}$ and $B_{1}$ are $2 \times 2$ coefficient matrices estimated by maximum likelihood, assuming a normal distribution for the demeaned $2 x 1$ vector $\epsilon_{t}$. Coordinates for parameter's position in respective matrix are (row position, column position). 


\section{Bibliography}

Ait-Sahalia, Y., J. Parker, and M. Yogo (2004, June). Luxury goods and the equity premium. Journal of Finance (59), 2959-3004.

Ashcraft, A., N. Gârleanu, and L. H. Pedersen (2010, September). Two monetary tools: Interest rates and haircuts. NBER working paper series (16337), 1-40.

Bernanke, B. and M. Gertler (1989, March). Agency costs, net worth, and business fluctuations. The American Economic Review (1), 14-31.

Bernardo, A. E. and I. Welch (2003, May). Liquidity and financial market runs. Yale ICF Working Paper (2-11), 1-33.

Bianchi, R. J. and M. E. Drew (2010, Apr). The role of ted spread and confidence index in explaining the behavior of stock prices. Griffith University, Department of Accounting, Finance and Economics in its series Discussion Papers in Finance (201004), 1-17.

Breeden, D. T. (1979, July). An intertemporal asset pricing model with stochastic consumption and investment opportunities. Journal of Financial Economics 7(1), 265296.

Brunnermeier, M. K. (2008, Dec). Deciphering the liquidity and credit crunch 2007-08. NBER Working Paper Series (14612), 1-33.

Brunnermeier, M. K. and L. H. Pedersen (2009, June). Market liquidity and funding liquidity. The Review of Financial Studies (6), 2201-2238.

Carlson, M. (2006, Nov). A brief history of the 1987 stock market crash, with a discussion of the federal reserve response. Board of Governors of the Federal Reserve (2007-13), $1-24$.

Cecchetti, S. G., H. Genberg, J. Lipsky, and S. Wadhwani (2000, May). Asset prices and central bank policy. International Centre for Monetary and Banking Studies (2), 1-152.

Engle, R. F. and K. F. Kroner (1995, Mar). Multivariate simultaneous generalized arch. Econometric Theory 11(1), 122-150.

Fama, E. F. and K. R. French (1993, June). Common risk factor in the returns on stocks and bonds. Journal of Financial Economics (33), 3-56.

Geanakoplos, J. (2010, June). The leverage cycle. Cowles Foundation Discussion Paper (1715), 1-55.

Giovannetti, B. C. and G. B. Martins (2011, September). Do margin requirements affect asset prices? mimeo (1), 1-35.

Gârleanu, N. and L. H. Pedersen (2011, April). Margin-based asset pricing and deviations from the law of one price. The Review of Financial Studies 24(6), 1980-2022.

Hedegaard, E. (2011, Nov). How margins are set and affect asset prices. Job Market Paper (1), 1-59. 
Kiyotaki, N. and J. Moore (1997, June). Credit cycles. Journal of Political Economy (105), 211-248.

Lashgari, M. (2000, Jun). The role of ted spread and confidence index in explaining the behavior of stock prices. American Business Review (1), 1-3.

Luttmer, E. G. J. (1996, November). Asset pricing in economies with frictions. Econometrica (6), 1439-1467.

Mankiw, G. N. and S. P. Zeldes (1991, June). The consumption of stockholders and nonstockholders. Journal of Financial Economics (29), 97-112.

Pastor, L. and R. Stambaugh (2003, June). Liquidity risk and expected stock returns. Journal of Political Economy (111), 642-685.

Shanken, J. (1990, June). Intertemporal asset pricing: An empirical investigation. Journal of Econometrics (45), 99-120.

Tsay, R. S. (2010). Analysis of Financial Time Series (3 ed.). Wiley-Interscience 2010, Probability and Statistics. 